Prejudice, Bigotry, and Support for Compensatory Interventions to Address BlackWhite Inequalities: Evidence from the General Social Survey, 2006-2020 *

\author{
Stephen L. Morgan \\ Johns Hopkins University
}

Forthcoming, Sociological Science

(Prior draft: November 15, 2021)

\footnotetext{
* Direct correspondence to Stephen L. Morgan (stephen.morgan@jhu.edu) at Department of Sociology, 3400 N. Charles St., Johns Hopkins University, Baltimore, MD 21218.
} 


\title{
Prejudice, Bigotry, and Support for Compensatory Interventions to Address Black- White Inequalities: Evidence from the General Social Survey, 2006-2020
}

\begin{abstract}
The General Social Survey (GSS) shows that many self-identified white adults continue to hold racial attitudes that can be regarded, collectively, as a persistent social problem. Similar to findings from the analysis of electoral surveys, the GSS also shows that these racial attitudes have more strongly predicted political behavior since 2012. However, and in contrast to groupidentity interpretations of these patterns, the increase in predictive power since 2012 is attributable to a positive development: above and beyond the effects of cohort replacement, support for compensatory interventions to address black-white inequalities has increased substantially, while prejudice and bigotry have decreased slightly. Because these changes have been larger on the political left than on the political right, the attitudes have gained in overall predictive power.
\end{abstract}




\section{Prejudice, Bigotry, and Support for Compensatory Interventions to Address Black- White Inequalities: Evidence from the General Social Survey, 2006-2020}

\section{Introduction}

Researchers who specialize in the analysis of social problems continue to monitor the racial attitudes of white adults. Two characterizations have emerged for the most recent trends. For the first, prejudice and bigotry have declined gradually because birth cohorts raised before the civil rights movement continue to be replaced by birth cohorts of individuals who are more highly educated and more accepting of multiracial and multiethnic diversity. For the second, increasing economic insecurity in an era of globalized trade, alongside divisive partisan politics, has accentuated collective resentment of the socioeconomic progress of non-white racial groups. In this article, I consider how these narratives align with findings from sociology's collective project to measure social change - the General Social Survey (GSS). ${ }^{1}$ I also argue for the likely importance of a third source of change since 2012: a resurgence in the movement for racial justice, which has raised awareness among white adults of the many remaining barriers to

\footnotetext{
${ }^{1}$ The General Social Survey has limitations, and a primary one should be mentioned upfront: its measurement of attitudes toward individuals usually referred to as "black or African-American" in survey items is much stronger and more consistent than its measurement of attitudes toward other groups. To some extent, the current racialattitudes coverage of the GSS reflects the longstanding concern of sociologists with understanding and interpreting the history of black-white inequality in America. It also reflects more recent dissensus among survey researchers on how best to fashion a reasonably compact set of questionnaire items that can disentangle attitudes toward new immigrants from attitudes toward individuals who identify with heterogeneous race-ethnic groups embedded in the over-broad categories of Hispanic and Asian. This dissensus was reflected most recently in the revisions selected by the GSS Board to the racial-attitudes battery, beginning with the 2018 survey. Rather than attempt to fashion new targeted measures of prejudice and bigotry for a wider range of groups, the Board instead selected a subset of everyday discrimination items, associated with the work of Bonilla-Silva $(1997,2003)$ and his colleagues. The rationale for the decision was the argument that a complement to traditional measures of prejudice and bigotry among majority white respondents is a set of measures that capture the experience of hostility and discrimination among all members of minority groups, which they experience as microaggressions. See Douds and Hout (2020) for an analysis of these new GSS items.
} 
racial equity. This movement is resonant with a simultaneous increase in support for progressive politics on the left, including greater interest in government intervention to address inequalities of all types.

In the sections below, I first offer relevant background from the literature that is needed to understand the approach that I take. Following an introduction to the data and measures, I then show that prejudice and bigotry remain more prevalent than presumed in lay pronouncements of a post-racial United States. Relatedly, support among white respondents remains low for compensatory interventions to address black-white inequalities in social standing. Consistent with journalistic portrayals since 2014, these measures also predict political outcomes, such as party identification and vote choice in presidential elections, and these relationships have strengthened meaningfully since 2012.

I then step back to consider closely the underlying attitudinal trends that generate current levels and changes in associations. I use a demographic model of change to show that the post-2012 period is distinctive because much of the change observed cannot be attributed to the compositional dynamics generated by cohort replacement. I then argue that the post-2012 period is best characterized by a positive period effect that cumulated progressively between 2014 and 2020. Beyond what would be expected from cohort replacement, white adults became more likely to indicate that they see anti-black discrimination and systemic disadvantage as problems that need to be addressed. Prejudice and bigotry have also declined in this period, although to a smaller degree.

These positive changes should not, however, be over-interpreted, and the article concludes with a discussion emphasizing the following points. Levels of prejudice and bigotry 
remain too high, and many more white adults oppose government interventions to address black-white inequalities than seems reasonable based on general beliefs about the role of government in promoting equality of opportunity. In addition, attitudes are but one set of measures. It is entirely possible, for example, that an increase in behavioral extremism among clearly prejudiced white adults can occur at the same time that attitudes, on the average, are shifting in a positive direction.

\section{Conceptual Background}

In this section, I discuss enough of the past literature on racial attitudes to orient readers unfamiliar with the prior research. As I present the empirical results, I discuss the most recent literature on how racial attitudes have evolved alongside the increases in multiracial diversity and political polarization of the twenty-first century.

Prejudice and bigotry. After Du Bois' classic study of the role that race prejudice played in maintaining black-white inequalities in Philadelphia (Du Bois 1899; see also Bobo 2000), Allport synthesized subsequent studies of prejudice and bigotry in his 1954 masterpiece, On the Nature of Prejudice. To introduce his approach, Allport begins with what he claims is the briefest of all useful definitions of prejudice ("thinking ill of others without sufficient warrant") and then develops the more complete definition of "antipathy based upon a faulty and inflexible generalization" that is "felt or expressed" and that "may be directed toward a group as a whole, or toward an individual" (see pages 6-9).

In the case of out-groups demarcated by racial and ethnic boundaries, Allport argues that prejudice has multiple sources that arise from interrelated causes, including interest-based responses to economic competition. Prejudice is nearly always supported by stereotypes that 
rationalize negative affect, and it can lead to an escalating scale of resulting behavior - from demeaning speech, to acts of discrimination, and finally to violence. The rationalizations of prejudice can be simple and direct, such as ignorant beliefs about human biology, but they can also be less obvious. Allport (1954:515) argues, for example, that "patriotism may be a mask for bigotry" and, on balance, "the superpatriotic nationalist" is "more often than not a thoroughgoing bigot."

In this article, I will rely on Allport's classic perspective for the portions in which prejudice and bigotry are the focus of analysis. While others may argue that Allport's perspective is deficient in one respect or another (see below), his perspective aligns well with many of the measures that are still in widespread use by analysts of racial attitudes. ${ }^{2}$ Antiblack prejudice is commonly measured by stereotype items that ask about biological differences (most commonly differences in intelligence or capacity for work hard), policy preferences for racial separation in public affairs (such as support for segregated schooling and neighborhoods), and personal preferences for race-based social distance (such as objections to a close relative marrying across racial lines).

Beyond prejudice and bigotry. In the seven decades since Allport's synthesis, scholars have debated how best to analyze racist attitudes using survey techniques. The debates consider three challenges: (1) the specific concepts, beyond prejudice and bigotry, that should be measured, (2) the questions that are most appropriate to place on survey instruments, and (3)

\footnotetext{
${ }^{2}$ Allport is sometimes misrepresented as claiming, above all else, that prejudice is a fixed personality trait. In fact, he focuses very clearly on the social-structural determinants of prejudice, which shape early socialization and then can be a source of dynamism throughout the lifecourse. His book concludes with an assessment of the variable effects of explicit interventions to reduce prejudice.
} 
the interpretations of the answers that are elicited from survey respondents, in light of disagreement over the concepts meant to be measured. The spiral of contestation results as much from the evolving substantive complexity of intergroup relations and our social conventions for discussing them as it does the sort of pure fractal contestation that Abbot (2001) argues is a common feature of scholarly debates.

Bobo, Charles, Krysan, and Simmons (2012) provide a thorough review of these debates as of 2012 with reference to the GSS, including for most of the measures that I will analyze below. ${ }^{3}$ Indeed, and at the risk of some oversimplification, it is Bobo and his colleagues' perspective that provides the most coherent approach to the analysis of racial attitudes. For them, as well as other sociologists who work within a multidimensional framework of interpretation, no single underlying concept or survey measure can be fashioned to capture racism. All measures differ in subtle ways, and an analyst can never be certain that respondents are interpreting survey questions as the survey designers intended. Indeed, in multiple articles and chapters, Bobo has advocated this position with reference to Allport's warning not to embrace "a sovereign explanation for all human prejudice" when an "eclectic" approach can offer much more insight because of the variation in forms of racism and its intensity (see Allport 1954: 207-8).

Within this framework of interpretation, prejudice and bigotry of the sort delineated by Allport is now often labeled "old-fashioned racism" or "Jim Crow racism." A consensus

\footnotetext{
${ }^{3}$ For additional reviews from the sociological literature, see Krysan (2000) and Schuman et al. (1998). See also Quillian (2006) for a discussion of how the literature on racial prejudice has evolved alongside the literature on discrimination. And, in part as critique of studies of expressed prejudice, Bonilla-Silva (1997) proposes a structural theory of racism that does not necessarily generate overt prejudice (see also Bonilla-Silva 2003).
} 
appears to exist that measures of prejudice and bigotry of this type can only offer an incomplete picture of racism in the contemporary United States. But exactly how that picture should be filled in has been contested.

In part as a reaction to dissensus within political science over new measures of “symbolic racism," Bobo, Kluegel, and Smith (1997; see also Bobo and Smith 1998) proposed that analysts consider the rise of "laissez-faire racism." Two points are key. First, opposition among white adults to compensatory interventions to address existing black-white inequalities is the essence of a new racism. Such opposition is a denial of the need to provide support to those who have been born into an unjust world and for whom many opportunities are blocked. Such views can be racist because, it is argued, they can only flourish strongly among white adults who regard other racial groups as inferior and thus less worthy of concern or assistance.

Second, a strain of laissez-faire racism can be found among white adults who do not object to compensatory interventions, but who nonetheless object to the pace of such interventions and whether they have been extended because of too much pressure. This collective resentment of black progress, as opposed to the denial of racial sympathy, can exist among white adults who profess a genuine desire to eliminate racial inequalities and who offer little or no evidence of prejudice or bigotry. Instead, these individuals appear motivated to preserve their own relative status, either personally or collectively, because they perceive group threat. $^{4}$

\footnotetext{
${ }^{4}$ Bobo and his colleagues are clear that many of these ideas can be found in the literature synthesized by Allport. What is new is the prevalence of laissez-faire rationalizations among elites, which emerged at the same time that many survey respondents learned that open support for Jim Crow racism had become social disapproved.
} 
Measurement of these new forms of racism remains controversial. The debate is most clear for the prior measures of symbolic racism developed by political scientists. I will discuss these distinctions within the presentation of the results, in direct relation to the measures that I analyze below. For now, it is sufficient to conclude that the sociological approach summarized above is complete enough to motivate the analysis in this article, much as it was for Bobo et al. (2012). The key is to analyze, along with traditional measures of prejudice and bigotry, what I will label support for compensatory interventions to address black-white inequalities.

\section{Data and Methods}

I analyze the cross-sectional samples of the GSS from 2006 to 2018, as well as the 2020 follow-up of the 2016 and 2018 GSS respondents (see Smith et al. 2019; Davern et al. 2021). I provide additional details of weighting procedures in the Supplement, including an attrition adjustment weight for the 2020 follow-up observations (based on the strategy explained in Morgan and Lee 2020). For this article, I select 2006 as the first year of analysis because substantial design changes to the GSS were all in place by then: a method of subsampling for non-response follow-up and a fully implemented Spanish-language questionnaire. In addition, from 2006 through 2018, the GSS field period began in the spring. ${ }^{5}$ As I show below, the 2006-2012 interval is a period of comparable stability, and it is thus a fitting baseline against which to study results from 2014 to $2020 .^{6}$

\footnotetext{
${ }^{5}$ The 2004 GSS was fielded five months later than typical, with interviews conducted between late August 2004 through the first few days of 2005.

${ }^{6}$ I do not use the recently released 2021 cross-sectional sample of the GSS in this article because the push-to-web design that was necessitated by the COVID pandemic represents a realized sample that has alternative coverage and response-rate complications that contribute to total survey error. Nonetheless, in my own preliminary analysis of the 2021 cross-sectional data, the changes presented in this article appear to be present in the 2021 cross-section as well. As explained below, I will use the 2020 follow-up of the 2016 and 2018 GSS cross-sections. These 2020 follow-up
} 
Race-ethnic groups. I consider four mutually exclusive subpopulations of adults, based on the GSS measures of multiracial and multiethnic self-identification:

(1) respondents who identify as white, non-Hispanic, and not multiracial,

(2) respondents who identify as black, non-Hispanic, and not multiracial,

(3) respondents who identify as Hispanic and non-Black, and

(4) respondents who identify as Asian, non-Hispanic, and not multiracial.

I will refer to these four groups with labels such as "white adults, "white people," "black adults," and "black people" (rather than "whites," "blacks", "African-Americans," etc.) in order to align with what appear to be coalescing as this decade's accepted semantics for group referents. I will also use the descriptors of Hispanic and Asian as well, and I recognize the large amount of heterogeneity that is present within these two groups.

Finally, and crucially, these four groups represent only 94 percent of the GSS crosssectional samples from 2006 through 2018.7 I do not mean to imply, for example, that nonHispanic multiracial respondents are not equally worthy of study. Instead, for analytic purposes, my goal is to eliminate objections to the findings below that they could be produced by hidden increases in the prevalence of multiracial and multiethnic identities. Thus, my analysis will be based only on the groups defined above, and especially the first group. Additional, and very worthwhile, work will be needed to determine how much additional change is present, for example, for an expanded "white" category that changes over time

\footnotetext{
observations are based on the same base year sampling design, and they have the advantage of enabling models of average within-individual change. With attrition weighting, the 2020 follow-up data are somewhat close to what a traditional GSS 2020 cross-sectional design probably would have yielded, at least close enough to analyze as such when appropriate caveats are maintained (such as minor under coverage on younger ages).

7 The additional 6 percent of the sample is composed primarily of individuals who select a non-Hispanic multiracial identity, a Hispanic and black identity, any identity that includes Native American or American Indian, or too little information on either ethnicity or race to be coded unambiguously in any broader group.
} 
because the share of white multiracial respondents is steadily increasing.

Outcomes. Table S1 in the Supplement presents the questionnaire wordings of the key racial attitude items that are present on all GSS questionnaires from 2006 through 2020, and I analyze these items on their own and in scales. I also model two political outcomes: a standard seven-category scale for party identification, from strong Democrat through strong Republican, and a self-reported vote for the Republican presidential candidate in the most recent general election.

Other measures. During the analysis, I introduce models of change that are structured by both birth cohort and observation year in order to examine how attitude change at the population level results from movement in each dimension of time. For adjustment through a demographic model, I use a two-category gender measure, a five-category educational attainment measure, and an 11-category measure of social class (see Morgan 2017 for details). The GSS offers many other measures of individuals that could be used to adjust results with a demographic model, but the key variation in the analysis is in the outcome measures themselves. Thus, a parsimonious set of race, class, and gender measures, when supplemented by an index of birth cohort, is sufficient to bring out the core pattern of results.

Model estimation. I use least-squares methods for model estimation. Logit and related models yield nearly identical results, but least-squares coefficients, as well as functions of them, are more easily interpreted. All estimated standard errors take account of the survey design.

\section{Results}

Table 1 presents levels of prejudice and bigotry for GSS respondents for the pooled 2014, 2016, and 2018 cross-sectional samples, separately by the groups and subgroups identified in the 
Additional groups for comparison with the "All" column

White-only, non-Hispanic for white-only, non-Hispanic

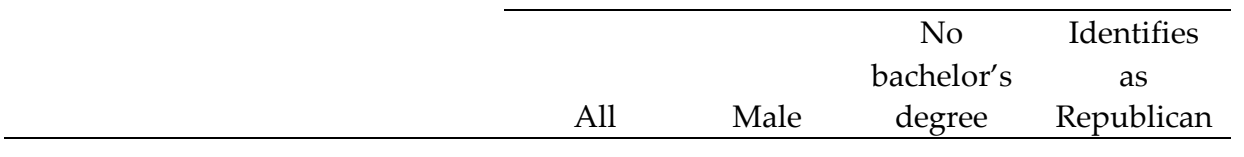

\begin{tabular}{ccc}
\hline $\begin{array}{c}\text { Black-only, } \\
\text { non- }\end{array}$ & Hispanic, & Asian-only, \\
non- \\
Hispanic & non-black & Hispanic \\
\hline
\end{tabular}

Preference for racial separation:

Would oppose a close relative marrying a black person

(MARBLK)

16.5

19.7

18.8

23.9

2.6

6.6

13.8

Would oppose a close relative

marrying a Hispanic or Latino

(0.8)

(1.2)

(1.0)

(1.6)

(0.7)

(1.0)

(3.3) person

(MARHISP)

11.1

(0.8)

12.8

(1.1)

13.3

(1.0)

15.5

(1.5)

6.1

2.2

(1.0)

(0.7)

7.3

Would oppose a close relative marrying an Asian American person 10.6

12.5

12.4

15.4

(7.0)

(1.5)

$(0.7)$

(1.0)

$2.6 \quad 3.0$

3.2

(0.4)

3.3

(0.6)

7.3

(1.0)

2.3

(0.8)

4.4

1.1

(1.1)

(0.8)

marrying a whi
(MARWHT)

\section{Racist stereotypes:}

Believe whites are more intelligent than blacks

(INTLWHTS, INTLBLKS)

Believe blacks are more lazy

than whites

(WORKWHTS, WORKBLKS)

(1.1)

32.1

21.9

24.7

25.7

(1.1)

(1.6)

20.1

(1.9)

29.7

(2.2)

43.6

(0.9)

(1.3)

34.5

(1.3)

40.6

(1.9)

27.6

(2.3)

47.4

(2.3)

54.2

(5.5)

\section{Attribution of causes of black-}

white inequalities:

"Because most blacks have less in-born ability to learn"

(RACDIF2)

$\begin{array}{cccc}6.6 & 6.4 & 8.7 & 7.6 \\ (0.5) & (0.7) & (0.7) & (0.9)\end{array}$

(0.9)

13.4

(1.4)

10.4

(1.6)

14.3

“Because most blacks just don't have the motivation or will power to pull themselves up out of poverty" (RACDIF4)

$\begin{array}{llll}39.6 & 38.3 & 46.5 & 52.3\end{array}$

(1.4) (1.9)

50.4

(2.2)
43.5 (5.6)

Notes: Standard errors in parentheses are estimated taking account of the survey design. Data are weighted to adjust for differential non-response by gender as well as to represent each biennial GSS sample equally. N's vary by question, due to patterns of missingness (usually "don't know"). The ranges are 3007-3103 for whites, 692-703 for blacks, 690-704 for Hispanics, and 127-130 for Asians. 
column headings. These three years of observations are weighted equally to cumulate cases for comparatively small race-ethnic groups, and the results in the table can be interpreted in analogous fashion to a smoothed data point located at the middle year of 2016.

The first four rows present results for the traditional measure of support for social distance and racial separation: relative opposition to interracial marriage. For white-only, nonHispanic respondents (hereafter, white respondents), opposition to a close relative marrying someone of another race is higher than general opposition to marriage within race. The level of opposition is highest for "a close relative marrying a black person." While in-group preferences are present for all groups, the levels of opposition to out-group marriage are higher among white respondents. Opposition is consistently above 10 percent and rises to as much as 23.9 percent among white respondents who identify as Republicans.

For racist stereotypes, the next two rows of Table 1 show that many white respondents believe that black people are less intelligent and lazier than are white people (21.4 and 30.9 percent, respectively). For white Republicans, the percentages are higher still at 25.7 and 40.6 percent.

For the final two rows of Table 1, which present results for the attribution of causes of black-white inequalities in housing, jobs, and income, 6.6 percent of white respondents believe that they are attributable to inborn ability to learn. A much larger 39.6 percent believe that the inequalities are attributable to a relative lack of motivation. For white Republicans, these attributions are more prevalent, at 7.6 and 50.2 percent, respectively.

One could argue that the measures in the final four rows of Table 1 reveal subtleties about how the words intelligence, hardworking, lazy, and in-born ability are interpreted by 
survey respondents. But the question wordings ask for attributions in a comparative context

(see Table S1 in the Supplement for the "mainly" wording), and the results should be

interpreted in this context. Respondents, for example, can believe that black people have less

inborn ability to learn while also believing that a lack of motivation is a more important source

of black-white inequalities. ${ }^{8}$

Regardless of how best to interpret the differences across the cells of Table 1, it cannot be

the case that prejudice and bigotry toward black people is no longer a substantial social

problem. On the contrary, many white adults offer answers on surveys that align with

characterizations of Jim Crow racism, even in an era when it is far less acceptable to publicly

denigrate black and Hispanic residents of the United States. ${ }^{9}$ Most public opinion researchers

believe that responses to questions on prejudice and bigotry are biased downward by social

desirability concerns in face-to-face interviews. Accordingly, in the absence of such bias, as

would be the case in private conversations among like-minded individuals, higher levels of

overt prejudice and bigotry would be expressed. These levels could be higher still if private

thoughts, unconstrained by any social conventions at all, could be tapped reliably.

\footnotetext{
${ }^{8}$ As the right-hand panel of Table 1 shows, these racist stereotypes are held, on average, by all four race-ethnic groups, even when they are the reference group of the stereotype. As with past research, it is unclear how to interpret these beliefs - the leading candidates being internalization of a harmful stereotype through repeated exposure, latent conservatism tied to a denial of structural barriers to advancement, or some type of within-group irreverence in response to the survey items, perhaps intended to be disingenuous and thus subversive.

${ }^{9}$ The attitudes of Asian respondents are most similar to those of white respondents, although estimated with much greater error. GSS respondents who self-identify as Asian, non-Hispanic, and not multiracial are the smallest of the four "big groups" considered in this article, but it is a group of considerable interest, both as a basis for comparisons and because it is growing disproportionately in size. Unfortunately, the GSS has a small under-coverage bias because (as of now) GSS questionnaires are available only in English and Spanish. Because of this under-coverage bias, the results for Asians should be interpreted with caution because of the increment to expected total survey error. Any inferences obtained may be more inaccurate than even a cautious approach to sampling error would already warrant.
} 
Table 2 presents corresponding results on levels of opposition to compensatory interventions to address black-white inequalities. Two thirds of white respondents believe that no special favors should be given to black people to help them overcome prejudice. One half do not feel that the government has a special obligation to raise the living standards of black people because of past discrimination. For the workplace, 84.1 percent of white respondents oppose the preferential hiring of black adults while 61.6 percent believe that some white adults are passed over for hiring and promotion by black adults who are less qualified. Opposition to all four types of compensatory support is highest for white respondents without bachelor's degrees and for those who identify as Republicans.

The patterns in Table 2 can be interpreted from different scholarly perspectives. At one end of the spectrum, these questions are direct measures of a new form of laissez-faire racism, for which it is acceptable to signal disapproval and denigration of black people by opposing compensatory policies. This disapproval and opposition can be expressed either as a false denial of remaining blocked opportunities or a lack of sympathy for how difficult it is to unblock them in the absence of compensatory assistance. At the other end of the spectrum, all responses are indications of principled policy positions against government interventionism and have only a tangential relationship to racial animus. I favor an intermediate position. Some meaningful heterogeneity is present in response to these questions, but nothing in Table 2 contradicts what is already suggested by Table 1 . The share of white respondents who have clearly racist attitudes may not be as high as the 60 percent or more that is implied by a rigid laissez-fair racism interpretation of Table 2, but the number is likely much higher than the lowest numbers in Table 1. 
Additional groups for comparison with the "All" column

White-only, non-Hispanic for white-only, non-Hispanic

\begin{tabular}{|c|c|c|c|}
\hline & & No & Identifies \\
\hline All & Male & $\begin{array}{c}\text { bachelor's } \\
\text { degree }\end{array}$ & $\begin{array}{c}\text { as } \\
\text { Republican }\end{array}$ \\
\hline
\end{tabular}

Black-only,
non-
Asian-only,

Hispanic

non-black Hispanic

\section{General support:}

Prefer no special favors be given to black people to help overcome prejudice (WRKWAYUP)

$\begin{array}{llll}66.3 & 66.0 & 73.9 & 79.3 \\ (1.1) & (1.6) & (1.3) & (1.7)\end{array}$

46.2

69.3

60.3

Disagree that the government has a special obligation to raise the living standards of blacks because of past discrimination and agree that no special treatment should be given (HELPBLK)

$\begin{array}{lllllll}52.8 & 53.0 & 55.2 & 73.1 & 13.9 & 38.4 & 33.4 \\ (1.1) & (1.5) & (1.3) & (1.7) & (1.4) & (2.1) & (4.2)\end{array}$

\section{Affirmative action in} employment: Oppose preferential hiring and promotion of blacks (AFFRMACT)

84.1

84.3

86.2

(1.0)

(1.1)

(1.0)

Believe it is likely white people are passed over for jobs and promotions in favor of less qualified black people (DISCAFF)

$\begin{array}{lll}61.6 & 58.6 & 66.0 \\ (1.1) & (1.4) & (1.3)\end{array}$
(2.5)

(2.0)

Notes: Standard errors in parentheses are estimated taking account of the survey design. Data are weighted to adjust for differential non-response by gender as well as to represent each biennial GSS sample equally. N's vary by question, due to patterns of missingness (usually "don't know"). The ranges are 3007-3103 for whites, 692-703 for blacks, 690-704 for Hispanics, and 127-130 for Asians. 


\section{Increasing associations between racial resentment and political behavior. Political}

scientists have devoted considerable attention to the effects of racial attitudes on the political behavior of white voters. Most recently, many political scientists have shown that the associations between measures of "racial resentment" and vote choices have increased in recent years, usually based on the analysis of electoral surveys such as the American National Election Studies (ANES). In this section, I present a parallel analysis of these associations, using the GSS data, to show that a general population survey yields a similar pattern. I will then discuss alternative interpretations, from the ones favored in the recent political science literature to plausible alternatives.

The GSS does not include all four of the exact ANES measures used by political scientists to construct a scale of racial resentment. ${ }^{10}$ The four agree-disagree items on the ANES are:

1. Irish, Italians, Jews and many other minorities overcame prejudice and worked their way up. Blacks should do the same without any special favors.

2. Generations of slavery and discrimination have created conditions that make it difficult for blacks to work their way out of the lower class.

3. Over the past few years, blacks have gotten less than they deserve.

4. It's really a matter of some people not trying hard enough; if blacks would only try harder they could be just as well off as whites.

Of these four items, only the first is present on the GSS as WRKWAYUP (already analyzed above in the first row of Table 2). Among the many symbolic racism items that entered the literature in the 1980s, WRKWAYUP was judged the most promising for the GSS because it

\footnotetext{
${ }^{10}$ For an explanation of the origins of the scale in the 1980s, see Henry and Sears (2002), which considers a broader range of items (eight of which they propose be utilized). Sears (1988), Kinder and Sanders (1996), Kinder and Kam (2009), and Kinder and Dale-Riddle (2012) explain the history of the fielding of the items on the ANES and how the four items in the main text became dominant by the time analysts turned to a consideration of the 2016 election.
} 
primed group comparisons, especially among white respondents in the 1990s who could have observed Irish and Italian immigrants overcoming prejudice and working their way up in prior decades. Thus, WRKWAYUP was added to the GSS in 1994 because it could reveal a core feature of new ideas about symbolic racism - resentment that black adults had not worked hard enough to get ahead and were instead relying too much on government assistance - while also aligning with sociologists' longstanding interest in group competition perspectives on racial prejudice.

The other three racial resentment items above are not included on the GSS, but effective scales of racial resentment have been constructed for the GSS using similar items. ${ }^{11}$ In addition to WRKWAYUP, Kinder and Kam (2009) and Tesler and Sears (2010), for example, use a scale with two additional GSS measures (see Table S1 in the Supplement): RACDIF1 (for denial of discrimination) and RACDIF4 (for the belief that a lack of motivation and will power among black people explains disproportionate rates of poverty). To these four variables, Tesler (2016) adds the racial stereotypes on hard work and laziness (WORKWHTS, WORKBLKS). The claim is that these GSS versions of the racial resentment scale have the key features of the ANES scale composed of the four items listed above. In this section, I follow the lead of these scholars to examine the associations of racial resentment with political outcomes in the GSS.

\footnotetext{
${ }^{11}$ I focus in this section on the work of political scientists, but sociologists have also contributed to this line of work. Tuch and Hughes (2011), for example, compare the standard ANES scale with an alternative constructed from the GSS items WRKWAYUP, RACDIF1, and RACDIF4. They show that both the GSS and the ANES scales perform similarly, and they do not argue for the superiority of the ANES scale. They argue that racial resentment is a powerful explanation of views toward racial policy items, even when racial resentment is measured in slightly different ways by different surveys. Hout and Maggio (2021) use a similar GSS scale as well as the ANES data in order to show similar trajectories, while detailing the partisan deflections through 2018 that were first published for the GSS by media sources (e.g., Clement and Guskin 2019).
} 
Table 3 presents two coefficients each from 12 separate least squares models estimated for white respondents in the pooled 2010, 2012, 2014, 2016, and 2018 samples. The two outcome variables are a standard seven-point scale for self-reported party identification and an indicator variable for whether the respondent voted for the Republican presidential candidate in the most recent general election (excluding from the sample for these models all respondents who did not vote). Six separate models (by row) are estimated for each outcome. The regression specification has this general form:

$$
y_{i}=\hat{\alpha}+\hat{\beta}_{1} \text { attitude }_{i}+\hat{\beta}_{2}\left(\text { attitude }_{i} \times \text { period }_{i}\right)+\hat{\beta}_{3} \operatorname{period}_{i}+\widehat{\boldsymbol{\beta}}_{4} \boldsymbol{x}_{i}+\epsilon_{i}
$$

where the focal attitude predictor is interacted with a period indicator and where $\widehat{\boldsymbol{\beta}}_{4} \boldsymbol{x}_{i}$ is a vector of adjustment variables multiplied by a conformable vector of regression coefficients.

For the models in Table 3, the period indicator references 2016 and 2018, in contrast to a reference category of 2010 through 2014. The adjustment variables are indicators for selfidentified gender and level of educational attainment. In Table 3, I present the coefficient estimates only for $\hat{\beta}_{1}$ and $\hat{\beta}_{2}$ from the 12 underlying models.

For the first row, I use the GSS coding of old-fashioned racism proposed by Tesler (2016), which is simply a contrast coding of two of the interracial marriage items from Table 1 above (see the Supplement for details). The first and third columns present values for $\hat{\beta}_{1}$ that show that old-fashioned racism is associated with both party identification and vote choice during the reference period of 2010 through 2014. Each increase in Tesler's five-point scale is associated with an increase of 0.244 points on the seven-point party identification scale toward 
Table 3. Results from twelve least squares models of change in the net predictive power of measures of old-fashioned racism and racial resentment for white-only, non-Hispanic respondents

Outcome:

Party identification scale

(1 for strong Democrat

to 7 for strong Republican)

First period

regression

coefficient

(2010-2014) second period (2016-2018)
Outcome:

Voted for Republican

presidential candidate

$(1=$ Yes, $0=$ No $)$

First period

regression Difference for

coefficient second period (2010-2014) (2016-2018)

Predictor (in separate models)

0.244

Old-fashioned racism scale

(0.042)

0.010

0.083

$-0.021$

(5 categories, MARWHT and

$(0.060)$

(0.009)

(0.023)

MARBLK)

Racial resentment scale

0.601

0.186

0.198

0.050

(standardized)

(0.047)

(0.063)

(0.011)

$(0.019)$

Items in racial resentment scale:

Discrimination responsible

for black-white differences

(RACDIF1)

Lack of motivation among

blacks responsible (RACDIF4)

No special favors for blacks

(WRKWAYUP reversed)

Blacks less hard working and

more lazy than whites

(WORKBLKS, WORKWHTS)

$\begin{array}{cccc}-0.918 & -0.436 & -0.297 & -0.154 \\ (0.097) & (0.147) & (0.030) & (0.053) \\ & & & \\ & & & 0.132 \\ 0.722 & 0.266 & 0.245 & (0.049) \\ (0.095) & (0.136) & (0.028) & \\ & & & 0.019 \\ 0.460 & 0.114 & 0.151 & (0.017) \\ (0.035) & (0.050) & (0.010) & \\ & & & 0.034 \\ 0.121 & 0.104 & 0.052 & (0.022) \\ (0.038) & (0.059) & (0.011) & \end{array}$

Notes: Standard errors in parentheses are estimated taking account of the survey design. Data are weighted to adjust for differential non-response by gender as well as to represent each biennial GSS sample equally. The old-fashioned racism scale is coded as described in Tesler (2016) and has five categories based on a contrast coding of opposition to intermarriage. The racial resentment scale is fashioned on Tesler (2016), but for this table it is standardized to the same scale as for all other tables (mean 0 and standard deviation of 1 over for the pooled 2006-2020 data, with the four items above first scaled in a graded response IRT model). All models include an indicator variable for self-identified gender as well as four indicator variables for the five categories of educational attainment (GSS variable DEGREE). 
the Republican pole and with an increase of 0.082 in the probability of voting most recently for the Republican presidential candidate. The second and fourth columns present values for $\hat{\beta}_{2}$, as 0.010 and -0.021 respectively. These values suggest that these associations did not change appreciably after 2014. The coefficients indicate only a very slight strengthening and weakening of the net cross-sectional relationships in the later time period, each of which could be the result of sampling error alone.

The second row, in contrast, shows a different pattern for Tesler's racial resentment scale. For the reference period of 2010 to 2014, each standard deviation increase in racial resentment is associated with an increase of 0.601 on the party identification scale toward the Republican pole and with an increase of 0.198 on the probability of voting for the Republican presidential candidate. The second and fourth columns then show that these relationships strengthened considerably after 2014, with estimated coefficients for the cross-product interaction terms equal to 0.198 and 0.050 , respectively. The first coefficient is well beyond what one could expect from sampling error alone, and the second is less so (but still larger than conventional cutoffs). The final four rows of Table 3 then demonstrate that the component items of the racial resentment scale align with the expected increases in associations for the scale as a whole, suggesting that no one component of the standardized composite scale is driving the overall increase in the associations with racial resentment.

While similar patterns have been shown with ANES data and other election surveys (see citations below), the GSS is not an election survey. Two important features should be noted before proceeding. First, the GSS samples the full adult population, not just citizens who have 
the right to vote. As a result, the party identification variable applies to anyone who chooses to express a party identification, including those who are not eligible to vote (but may expect to become eligible to vote in the future). Second, the GSS is conducted every two years, with most data collection between May and August (i.e., not every four years as with the ANES, and not in close proximity to election day). The spring-summer fielding period results in retrospective reports of vote choice that do not correspond to the election held in that year. For the 2012 and 2016 GSS data, for example, the reported votes are for the 2008 and 2012 elections, respectively. Because of these timing differences, I offer additional results in the Supplement that vary the years in the analysis (2006 through 2018 in Table S2, 2010-2020 in Table S3, and 2014 and 2018 only in Table S4). These extended results suggest that a general trend is at play rather than a specific and narrow response to an election cycle, such as the 2016 presidential election.

Overall, the results in Table 3, along with those in the Supplement, are broadly consistent with work in political science that shows an increase in the predictive power of racial resentment in models of political behavior for white voters. How should we interpret the pattern of an increasing association in the GSS and in other data sources?

Several possible interpretations have been proposed, and the most common is associated with the work Sides, Tesler, and Vavreck (2018). ${ }^{12}$ They argue that the key factor is the increased salience of group identity for political behavior, especially the activation of racial identity during the 2016 primary and general election campaigns. While old-fashioned racism continued to predict political predispositions as expected, Donald Trump succeeded in

\footnotetext{
12 See also Abramowitz and McCoy (2018). Jardina (2019) argues, somewhat differently, that white racial solidarity and consciousness increased during the 2016 election campaign, which provided a source of support for a stronger connection between racial resentment and political behavior.
} 
convincing many white voters, especially those without college degrees, to adopt a racialized understanding of their own anxieties, whether cultural or economic.

A standard contrarian interpretation from the literature on racial resentment would be based on the claim that the racial resentment scale is a measure of general attitudes toward government intervention and thus ideological conservatism of the small-government form. ${ }^{13}$ While there may be some value in this type of argument for some respondents in some time periods, the recent literature in political science appears to give no attention to this interpretation for the increasing predictive power of racial resentment. Indeed, the same scholars who favor group identity explanations have shown that the inclusion of direct measures of conservatism and government involvement in multiple regression models (e.g., Sides et al. 2018, Tables A8.1 and A8.2) does not account for the increase in the associations. Accordingly, no one seems to claim that the increasing predictive power of racial resentment since 2012 reflects an underlying increase in pure ideological distance between partisan voters.

A third alternative interpretation is also available, and it requires a discussion of the original measurement motivation of the work in political science. When presenting their scale of racial resentment, Kinder and Sanders (1996:106) explained that "the questions distinguish between those whites who are generally sympathetic towards blacks and those who are generally unsympathetic." The number of white adults approaching the unsympathetic pole, which Kinder and Dale-Riddle (2012:175) later described as having a "collection of complaints," has always been larger than the number of white adults approaching the opposite pole, using

\footnotetext{
13 The general argument is debated at length in Sears, Sidanius, and Bobo (2000), following the work that began in pieces such as Sniderman and Tetlock (1985).
} 
the standard scaling methods in the political science literature. As such, it was (and remains) appropriate to label the scale racial resentment rather than racial sympathy. ${ }^{14}$

The expectation at the time the resentment label was chosen was that variation along the scale would be related to, but nonetheless distinct from, scales of prejudice. And, at the time, it was unclear whether a group threat perspective was essential to understanding the variation, as sociologists such as Bobo were arguing in other work. In theory, one could have a middling value on the racial resentment scale and not feel any group threat, while also being very different from those at the racial sympathy pole, who would be regarded today as progressive antiracists.

With this understanding of the scale, a complementary interpretation is available, which is suggested by a simple pole-switch in semantics: racial sympathy now has a stronger relationship with political behavior. This contrarian interpretation might be a better interpretation, if it is the case that the number of white adults at the racial sympathy pole of the scale has increased at the same time that the association of the scale with political behavior has also increased. A plausible mechanism here could then be that the movement for racial justice has generated more racial sympathy among white adults since 2012, and, furthermore, that the sympathy has accumulated disproportionately on the political left. The key matter to

\footnotetext{
${ }^{14}$ Kinder and Sanders (1996:299) indicate that their "new terminology" of "racial resentment" (as opposed to the original "symbolic racism") was selected to refer to the sort of "moral resentments" investigated in earlier research on suburban white Los Angeles voters. The "collection of complaints" rationale cited in the main text is possibly a better way of explaining what they meant, made necessary by the criticism that they received (see Sears, Sidanius, and Bobo 2000). Characterizing racially unsympathetic white adults as signaling that they are resentful has been harder to justify, in part because dictionary definitions of the word resentful are inward directed and focus on one's own sense of bitterness at having been treated unfairly. Place-based notions of resentment offer a useful comparison. Cramer (2016) argues that individuals in rural areas often resent the lack of investment in their communities, which they regard as unfair relative to the greater investments they feel have been made in urban and suburban communities.
} 
investigate, then, is differential movement along the scale of racial resentment toward the racial sympathy pole.

\section{Period effects revealed as departures from a model of underlying demographic}

change. While the results in Table 3 can be interpreted in a way that is quite discouraging, the GSS permits a balanced analysis of alternative interpretations. The period shifts shown in the associations of Table 3 do not reveal underlying change in the levels of the predictors. As I foreshadowed in the introduction, the GSS allows for the careful modeling of gradual change through cohort replacement, which is a first step toward assessing whether recent attitude change is distinctive, after which the full pattern of change can then be analyzed.

Because the focus of concern remains the attitudes of white adults, I continue to restrict the analysis to white respondents only in this section (but I offer results in the Supplement for other groups). The approach I have chosen for this section of results has four steps:

1. Use the 2006 through 2012 GSS data to fit a demographic model of change.

2. Use the parameters from the estimated model in step 1 to project counterfactual change in the interval from 2014 through 2020, as if attitudes evolved after 2012 only in ways that can be entirely attributed to the continuing effects of demographic change.

3. Assess whether all observed attitude change after 2012 can be attributed solely to demographic change.

4. If a portion of the observed change after 2012 cannot be attributed to demographic change, then (a) characterize the incremental change as an emergent period effect after 2012 and (b) examine its heterogeneity across individuals.

I demonstrate the first three steps of this approach in detail in the Supplement. For the results in this section of the main text, I present only the third and fourth steps which deliver the key substantive results.

Table 4 specifies three outcome variables - the same racial resentment scale modeled for Table 3, as well two scales that match the substantive foci used above to 
Table 4. Least squares models for period effects on scales of racial resentment, prejudice and bigotry, and opposition to compensatory support for white-only, non-Hispanic respondents, 2006-2020

\begin{tabular}{|c|c|c|c|c|c|c|}
\hline & \multicolumn{2}{|c|}{ Racial resentment } & \multicolumn{2}{|c|}{ Prejudice and bigotry } & \multicolumn{2}{|c|}{$\begin{array}{c}\text { Oppose compensatory } \\
\text { support }\end{array}$} \\
\hline & Raw & Increment & Raw & Increment & Raw & Increment \\
\hline \multirow[t]{2}{*}{2006} & 0.073 & 0.020 & 0.061 & -0.019 & -0.025 & -0.055 \\
\hline & $(0.060)$ & $(0.058)$ & $(0.063)$ & $(0.059)$ & $(0.042)$ & $(0.042)$ \\
\hline \multirow[t]{2}{*}{2008} & 0.090 & 0.043 & 0.071 & 0.002 & -0.022 & -0.047 \\
\hline & $(0.061)$ & $(0.057)$ & $(0.063)$ & $(0.059)$ & $(0.047)$ & $(0.046)$ \\
\hline \multirow[t]{2}{*}{2010} & 0.015 & -0.010 & 0.031 & -0.014 & -0.046 & -0.053 \\
\hline & $(0.060)$ & $(0.057)$ & $(0.062)$ & $(0.057)$ & $(0.045)$ & $(0.044)$ \\
\hline 2012 & -- & -- & -- & -- & -- & -- \\
\hline \multirow[t]{2}{*}{2014} & -0.026 & -0.023 & -0.066 & -0.067 & -0.057 & -0.059 \\
\hline & $(0.066)$ & $(0.063)$ & $(0.066)$ & $(0.060)$ & $(0.045)$ & $(0.043)$ \\
\hline \multirow[t]{2}{*}{2016} & -0.212 & -0.193 & -0.141 & -0.112 & -0.288 & -0.279 \\
\hline & $(0.069)$ & $(0.066)$ & $(0.063)$ & $(0.059)$ & $(0.045)$ & $(0.043)$ \\
\hline \multirow[t]{2}{*}{2018} & -0.327 & -0.294 & -0.225 & -0.178 & -0.403 & -0.381 \\
\hline & $(0.072)$ & $(0.068)$ & $(0.065)$ & $(0.061)$ & $(0.049)$ & $(0.047)$ \\
\hline \multirow[t]{2}{*}{2020 followup } & -0.368 & -0.317 & -0.192 & -0.118 & -0.443 & -0.412 \\
\hline & $(0.075)$ & $(0.071)$ & $(0.071)$ & $(0.067)$ & $(0.056)$ & $(0.054)$ \\
\hline \multirow[t]{2}{*}{ Intercept } & 0.173 & -0.014 & 0.050 & 0.008 & 0.342 & 0.039 \\
\hline & $(0.049)$ & $(0.047)$ & $(0.049)$ & $(0.044)$ & $(0.031)$ & $(0.030)$ \\
\hline R-squared & 0.029 & 0.021 & 0.012 & 0.004 & 0.032 & 0.028 \\
\hline $\mathrm{N}$ & 7854 & 7854 & 7849 & 7849 & 11511 & 11511 \\
\hline
\end{tabular}

Notes: Standard errors in parentheses are estimated taking account of the survey design. Data are weighted to adjust for differential non-response by gender as well as to represent each biennial GSS sample equally. The racial resentment scale is the same one as for Table 3. It is detailed in the main text and in the Supplement, along with the other two outcome scales that correspond to items, respectively, from Tables 1 and 2. 
differentiate Table 1 on prejudice and bigotry from Table 2 on opposition to compensatory interventions to address black-white inequalities. The coefficients in Table 4 can be directly compared across all columns because all three outcomes have been scaled to have a standard deviation of 1 over the full 2006-2020 pooled sample (with each year weighted equally). In particular, the standardization permits relative comparisons, conditional on the total variation within each scale over the full time period. For comparisons of absolute change in the components of the scales, I provide in the Supplement separate models with the specific indicators as the outcomes (see Table S12).

For the models in Table 4, two sets of coefficients are presented for each outcome. The coefficients reported in each "Raw" column are for indicator variables for the relevant GSS years, with the reference year set at 2012. No other adjustment variables are specified for these models, and thus the coefficient estimates reveal observed change over time. The coefficients reported in each "Increment" column have the same regressor specification, but the outcome has been residualized through steps 1 and 2 delineated above. As fully explained in the Supplement, the component of overall change that is attributable to baseline demographic change through cohort replacement has been removed from the outcome for the "Increment" columns. Thus, these models reveal the increment of change that is attributable to the period effect that accumulates after 2012.

The first two columns show decreases in racial resentment from 2012 through 2018, which cumulate steadily after only a small change in 2014. These decreases are reduced in magnitude by approximately twenty percent in 2016 and 2018 after the consequences of baseline demographic change are removed from the trend. 
The results in the next four columns are similar, except in the amount of change. The middle two columns show decreases in prejudice and bigotry from 2012 through 2018, which are slightly smaller than for racial resentment. The last two columns show decreases for opposition to compensatory support that are larger than for both racial resentment and prejudice and bigotry. Moreover, proportionately less of the raw change for opposition to compensatory support can be attributed to baseline demographic change through cohort replacement. In other words, the cumulating period effect between 2012 and 2018 is largest for opposition to compensatory support.

Note also that the models in Table 4 fit coefficients for 2020, labeled slightly differently as "2020 follow-up." These coefficients require additional explanation. In brief, the coefficients refer to the 2020 follow-up of the 2016 and 2018 GSS respondents (see the Supplement for a full explanation). The inclusion of the 2020 observations in the models in Table 4 can be seen as a separable add-on because their inclusion does not otherwise change the other coefficients (i.e., they do not contribute information that affects the comparison of other years to 2012). What the 2020 coefficients show is that the decline through 2018 in prejudice and bigotry may have stabilized in 2020 (as the value of each coefficient is generally midway between the coefficients for 2016 and 2018, suggesting that the 2020 levels are a mixture of the 2016 and 2018 levels that the same respondents reported when they were surveyed at the baseline). For racial resentment and opposition to compensatory support, however, the change appears to have been extended into 2020, as the coefficients are more negative in all cases than the corresponding coefficients for 2016 and 2018. 
These 2020 follow-up results are therefore consistent with what is shown for the coefficient estimates for the years 2014 through 2018. For 2020, prejudice and bigotry declined less than did racial resentment and opposition to compensatory support. And more of the decline for prejudice and bigotry by 2020 is attributable to demographic change. The Supplement offers an additional model that focuses on within-individual change only, and it also aligns with this conclusion.

The coefficient estimates in Table 4 do not reveal whether change varies by individuallevel characteristics, such as level of education or party identification. Accordingly, Tables 5 presents summaries of changes estimated in Table 4 (but dropping the 2020 follow-up data points for simplicity). The summaries in Table 5 are smoothed linear fits to yearly change after 2012, with the reference period set as the pooled 2006-2012 sample. In the first two rows, gender differences in change are presented, both for raw change on each scale and for the increment that is not attributable to underlying demographic change.

Gender differences for all three outcomes are modest, and the estimated yearly decline is between 0.04 and 0.06 standard deviations per year, depending on the outcome. These yearly changes cumulate between 2012 and 2018 to total changes in the range of 0.24 to 0.36 standard deviations, aligning with what is shown Table $4 .{ }^{15}$

Differential change by level of educational attainment is more substantial. Individuals in the middle of the distribution appear to be changing the most, and thus they are catching up

\footnotetext{
${ }^{15}$ In the Supplement, I offer additional summaries that include the 2020 follow-up observations as well, and the same basic interpretations emerge. I favor the up-to-2018 results in the main text in order to align with the analysis presented in Table 3. See Table S13 for a parallel set of models that uses the 2010-2020 interval (i.e., adding 2020 and dropping 2006 and 2008).
} 
Table 5. Raw and incremental change per year for the period effects on racial attitudes from 2012 through 2018 for white-only, non-Hispanic respondents

\begin{tabular}{|c|c|c|c|c|c|c|}
\hline & \multicolumn{2}{|c|}{ Racial resentment } & \multicolumn{2}{|c|}{ Prejudice and bigotry } & \multicolumn{2}{|c|}{$\begin{array}{c}\text { Oppose compensatory } \\
\text { support }\end{array}$} \\
\hline & Raw & Increment & Raw & Increment & Raw & Increment \\
\hline \multicolumn{7}{|l|}{ Gender: } \\
\hline \multirow[t]{2}{*}{ Male } & -0.065 & -0.055 & -0.045 & -0.030 & -0.068 & -0.063 \\
\hline & $(0.011)$ & $(0.010)$ & $(0.010)$ & $(0.010)$ & $(0.008)$ & $(0.008)$ \\
\hline \multirow[t]{2}{*}{ Female } & -0.059 & -0.046 & -0.045 & -0.026 & -0.058 & -0.051 \\
\hline & $(0.010)$ & $(0.010)$ & $(0.009)$ & $(0.009)$ & $(0.007)$ & $(0.007)$ \\
\hline \multicolumn{7}{|l|}{ Educational attainment: } \\
\hline \multirow[t]{2}{*}{ No HS diploma } & -0.008 & 0.003 & -0.018 & -0.002 & -0.032 & -0.027 \\
\hline & $(0.020)$ & $(0.020)$ & $(0.025)$ & $(0.025)$ & $(0.016)$ & $(0.016)$ \\
\hline \multirow[t]{2}{*}{ HS diploma } & -0.061 & -0.054 & -0.054 & -0.042 & -0.060 & -0.056 \\
\hline & $(0.010)$ & $(0.009)$ & $(0.010)$ & $(0.009)$ & $(0.007)$ & $(0.007)$ \\
\hline \multirow[t]{2}{*}{ Some college } & -0.062 & -0.055 & -0.061 & -0.049 & -0.045 & -0.041 \\
\hline & $(0.021)$ & $(0.021)$ & $(0.021)$ & $(0.022)$ & $(0.016)$ & $(0.016)$ \\
\hline \multirow[t]{2}{*}{ Bachelor's degree } & -0.077 & -0.073 & -0.029 & -0.020 & -0.086 & -0.083 \\
\hline & $(0.013)$ & $(0.013)$ & $(0.012)$ & $(0.012)$ & $(0.011)$ & $(0.011)$ \\
\hline \multirow[t]{2}{*}{ Graduate degree } & -0.038 & -0.024 & -0.006 & 0.014 & -0.043 & -0.037 \\
\hline & $(0.020)$ & $(0.021)$ & $(0.016)$ & $(0.017)$ & $(0.017)$ & $(0.017)$ \\
\hline \multicolumn{7}{|l|}{ Party Identification: } \\
\hline \multirow[t]{2}{*}{ Democrat (excluding leaners) } & -0.116 & -0.099 & -0.069 & -0.047 & -0.118 & -0.106 \\
\hline & $(0.015)$ & $(0.013)$ & $(0.014)$ & $(0.014)$ & $(0.011)$ & $(0.011)$ \\
\hline \multirow[t]{2}{*}{ Independents (including leaners) } & -0.058 & -0.045 & -0.041 & -0.022 & -0.057 & -0.049 \\
\hline & $(0.011)$ & $(0.010)$ & $(0.010)$ & $(0.011)$ & $(0.009)$ & $(0.009)$ \\
\hline \multirow[t]{2}{*}{ Republicans (excluding leaners) } & -0.033 & -0.026 & -0.029 & -0.018 & -0.030 & -0.025 \\
\hline & $(0.011)$ & $(0.011)$ & $(0.012)$ & $(0.011)$ & $(0.007)$ & $(0.008)$ \\
\hline $\mathrm{N}$ for gender and education & 7122 & 7122 & 7119 & 7119 & 10373 & 10373 \\
\hline $\mathrm{N}$ for party identification & 6887 & 6887 & 6883 & 6883 & 10025 & 10025 \\
\hline
\end{tabular}

Notes: See Table 4. The base for change is the pooled 2006-2012 sample, and the raw and incremental change are calculated by year from this base. See Table S13 in the Supplement for results using the 2010-2020 sample. 
to the lower levels of racial resentment, prejudice and bigotry, and opposition to compensatory support that are already more common among those with advanced educational degrees.

For clarity, it should be noted that these changes by education level are not adjusted for gender or any other characteristic, except for the second column in each pair in which the incremental change is the focus. For these latter columns, education also contributes to the underlying model of demographic change, which is purged from the outcome. The differences between the columns show how much of the education-related change is attributable to the underlying model and the net incremental change.

Finally, and most important for those interested in changes in racial resentment associations, differential change by party identification is much more substantial, leading to an accentuation of between-party-identification differences on racial attitudes since 2012. These growing differences after 2012 are not produced by an increase among Republicans in racial resentment, prejudice and bigotry, or opposition to compensatory support. In fact, Republicans are moving toward lower levels of prejudice and greater support for compensatory interventions. Their change is in the range of 0.02 to 0.03 per year, leading to six-year total declines of 0.12 to 0.18 standard deviations. Nonetheless, the change for Democrats is much more substantial, in the range 0.05 and 0.11 per year, leading to much larger six-year total declines of 0.30 to 0.66 standard deviations. Independents are in the middle.

Overall, Tables 4 and 5 suggest some positive period changes in the racial attitudes of white adults. Even after accounting for baseline declines that are attributable to cohort replacement, on average white respondents became less prejudiced, less bigoted, and more supportive of interventions to address black-white inequalities after 2012. Even those with the 
lowest levels of education and those who identify as Independents and Republicans trended, on average, in this direction. At the same time, the disparities in attitudes widened across party lines (and, thus, typical voting patterns did as well). The consequences of such widening are manifold, as discussed below, but the results are most consistent with the third characterization of the increasing racial resentment associations suggested above. White adults, on average, became somewhat more racially sympathetic after 2012 (see Table 4), but the increase in sympathy was greatest among white adults who identify as Democrats and smallest among white adults who identify as Republicans (see Table 5). As a result, the scale of racial resentment more strongly predicted party identification and vote choice after 2012 because of differential movement toward the racial sympathy pole of the scale.

\section{Conclusions and Discussion}

The racial attitudes of a large number of white adults remain a social problem. While it is not possible to determine conclusively the proportion of individuals who have racist attitudes, given a lack of consensus on how to define racism and how to interpret survey responses, it is not too incautious to conclude that more than 30 percent of white adults in recent years are willing to express some attitudes that can be reasonably interpreted as racist.

At the same time, attitude change since 2012 is in an encouraging direction, and this

change is not merely a knock-on effect of changing population composition. The prejudice and bigotry of white adults declined meaningfully, on average, beyond the amount that can be attributed to cohort replacement. In addition, their opposition, on average, to compensatory interventions to address black-white inequalities declined even more. A likely catalyst for these 
changes was the increased attention to the need for criminal justice reform, which activists on the left pushed forward with a higher level of media attention every year after 2012, especially following the death of Michael Brown in a police shooting in Ferguson, Missouri in August 2014.

The dynamics of party identification and attitude change. The results above conclude with the claim that, after 2012, Independents and Republicans became less prejudiced and bigoted and more supportive of compensatory interventions. Nonetheless, because Democrats moved even further in the same direction, the partisan gap in racial attitudes grew after 2012. When aggregate changes of this type emerge, it is common to consider the thicket of complications that arises from plausible narratives about how both attitudes and party identifications may have moved at the individual level, generating change that is sometimes labeled "party sorting." For most data sources, including the GSS, we do not have sufficient repeated measurements of individuals, across enough years, to offer empirical models of change that directly model party sorting.

One way to resolve the problem is to ignore it, seizing on a simplistic "polarization" argument driven by political elites. This position is based on the standard unmoved-mover position from political science: party identification is a powerful predictor of political behavior because it is stable and resistant to change. Accordingly, party sorting that results from shifting party identifications at the individual level can be ignored because individual-level movement is uncommon and evanescent. Instead, changes in beliefs, on average across party lines, are the result of effective persuasion, where individuals adopt the positions of the political elites affiliated with each party. If differences emerge across parties, then they can be attributed 
almost entirely to changes in the beliefs of the political elites affiliated with each party.

Contrary to this position, we have substantial recent evidence of shifts in party identification over time, especially since the 1990s among white adults with lower levels of education and working-class jobs (see Morgan and Lee 2017).

A related and more easily defended position would be to argue that we should focus our interpretations only on the aggregate pattern, pushing aside any underlying dynamism at the individual level. For this position, the focus should remain on point-in-time differences between groups of individuals who consider themselves to be aligned with particular political parties, and we should focus on how such point-in-time differences change as the political environment evolves. In other words, movement in party identification may well be more common than the traditional political science interpretation suggests, but such underlying movement is of secondary interest. Even if one could adjust comprehensively for individuallevel movement, one would then be analyzing change across a distorted aggregate pattern of party identification that would not fit the observed world in which political parties make appeals to voters.

While this second position has some analytic appeal, it is not inconsistent with a careful discussion of what might be unfolding as individuals change their beliefs and identifications. Indeed, I expect that, when all of the evidence is in, a consensus will emerge that a two-phase movement in party loyalties at the individual level is entangled with the pattern of change in racial attitudes across party lines. Individuals have sorted as political elites have polarized, and such patterns have affected the distribution of racial attitudes. 
First, it should be kept in mind that the aggregate trends are impossible to ignore, even if party sorting is entangled with subgroup trajectories in attitudes. White adults, in the aggregate, did move toward the racial sympathy pole on the racial resentment scale. The change was strongest for opposition to compensatory interventions, and these changes cannot be attributed to baseline underlying demographic change. While I have no direct evidence to offer in this article, I believe, as indicated above, that it is reasonable to infer that the campaign for racial justice played a role in generating these changes. Part of the effect of the activism was in forcing politicians to align themselves in relation to it, and so the unfolding politic dynamic from 2014 onward was racialized.

As part of that process, two groups of cross-pressured voters changed their political behavior. First, some comparatively prejudiced Democrats and Independents, who saw appeal first in the Tea Party movement and then later in the emergence of Donald Trump as a presidential aspirant, found Democratic candidates less attractive. These individuals became part of the "bandwagon bigotry" that was crucial for Trump's narrow victory in 2016 (see Morgan and Lee 2019). Second, many Republican voters supported Trump in 2016 because of party loyalty, suppressing their misgivings about his potential presidency. The least prejudiced members of this group became uncomfortable with Trump's approach to race relations, especially after he failed to repudiate the white supremacist rally in Charlottesville in $2017{ }^{16}$ Any hopes that he would govern as an establishment leader, as suggested by his business

\footnotetext{
${ }^{16}$ At that moment, it became clear to many that Trump would adopt a governing posture closer to the "The Program of the Demagogue" summarized by Allport (1954:410-24).
} 
background, were dashed by the end of 2017 . These voters then began to shift to the left in 2018, as they prepared to vote for centrist candidates in the midterms.

We do not know enough yet about these two groups of cross-pressured voters, in part because we do not know whether their vote-based disloyalty was strong enough to shift their answers to the political identification questions. For the sake of argument, I will assume that they did shift to some degree, moving locally, for example, from traditional party loyalists to leaning Independents.

Under this scenario, Democrats and Independents who moved to the right had racial attitudes similar to those of the typical Republican voter (see Morgan and Lee 2019). As a result, their movement into the group of Republican identifiers would not likely have changed the trajectory of the average racial attitudes of Republicans, all else equal. Nonetheless, their movement to the right would result in a decline in the average prejudice and bigotry among Democrats and Independents, perhaps even more so for support for compensatory interventions. Thus, this compositional shift could have accentuated the observed movement toward racial sympathy among Democrats and Independents, and the size of that accentuation would be a function of the prevalence of such movers.

We know less about individuals who identified as Republicans and Independents in 2016, but whose political behavior moved to the left thereafter. Many appear to believe that these individuals are more highly educated than other recent Republican voters, and results from further analysis of the 2020 election may confirm this inference. If so, this evidence may be enough to assert that departures from solid identification with the Republican party were largest among those who were the least prejudiced and the least opposed to compensatory 
interventions. Thus, in the absence of this compositional change, Republican identifiers

probably would have moved further in the same direction as Democrats, reducing polarization across parties, all else equal.

Altogether, I do not believe that we yet know how this two-phase shift in voting patterns is related to the trends documented in this article. The shifts may or may not have been strong enough to push individuals along the party identification scale. And, even if both were strong enough to shift party identifications, their effects could cancel each other out. We will need further research to assess these possibilities.

Caveat lector. Any discussion of compositional shifts, such as the party identification discussion just above, must also grapple with the potential for differential non-response to electoral surveys, such as the ANES, and general population surveys, such as the GSS. In an environment of declining survey participation rates, it is possible that the declines have been largest among those individuals who are the least willing to share their attitudes and opinions on contentious matters. ${ }^{17}$ To the extent that such individuals have higher than average levels of prejudice, the overall trends revealed by the GSS in this article may be biased toward change in racial attitudes when, in fact, less genuine change occurred.

This possible pattern deserves scrutiny but has been difficult to examine directly. The GSS may be susceptible, but it should be recognized that the GSS departs notably from the random-digit-dialed telephone surveys that are conducted over two or three days by political pollsters and media organizations. The GSS has an extended field period, uses escalating paid

\footnotetext{
17 The decline in the GSS response rate was substantial through 2018, but no decline in sample quality based on demographic characteristics was found (see Morgan 2020). This does not mean that all types of differential nonresponse are absent.
} 
incentives, and has honed its non-response follow-up protocols since 2000. Nonetheless, these protections may have been insufficient to prevent differential non-response, and, if so, then differential non-response could account for some of the trends in this article since 2012.

Finally, one should not over-interpret the positive attitude change that is suggested by this article for three reasons. First, it is possible that the positive trends in racial sympathy are superficial. For example, social desirability bias may have begun to shape survey responses to questions on compensatory support for addressing black-white inequalities. More white adults may feel that they are expected to respond in ways that suggest that they support the movement for racial justice, even if they do not genuinely support it. Second, it has long been recognized that genuine changes in attitudes do not necessarily lead to changes in behavior. Instances of everyday discrimination, for example, may not decline by any meaningful amount in response to attitude change. Third, it is possible for racist behavior to increase as racial prejudice and related attitudes, on average, moderate. In such an environment, those who advocate for the preservation of white supremacy might work harder to promote their cause, either because they are emboldened by transitory political dynamics or because they interpret an increase in racial sympathy as growing white disloyalty that must be countered.

Because of these possibilities, it would be naïve to over-interpret the relevance of the positive change reported in this article. The range of plausible trajectories for future intergroup relations is wide, and a full picture will only emerge when we can determine how changes in racial attitudes since 2012 are related to changes in relevant behavior. 


\section{References Cited}

Abbott, Andrew D. 2001. Chaos of Disciplines. Chicago: University of Chicago Press.

Abramowitz, Alan and Jennifer McCoy. 2018. “United States: Racial Resentment, Negative

Partisanship, and Polarization in Trump's America." The Annals of the American Academy of Political and Social Science 681(1):137-56. doi: 10.1177/0002716218811309.

Allport, Gordon W. 1954. The Nature of Prejudice. Cambridge: Addison-Wesley.

Bobo, Lawrence, James R. Kluegel, and Ryan A. Smith. 1997. “Laissez-Faire Racism: The Crystallization of a Kinder, Gentler Antiblack Ideology." in Racial Attitudes in the 1990's: Continuity and Change, edited by S. A. Tuch and J. K. Marin. Westport, CT: Praeger Press.

Bobo, Lawrence and Ryan A. Smith. 1998. "From Jim Crow Racism to Laissez-Faire Racism: An Essay on the Transformation of Racial Attitudes in America." in Beyond Pluralism: Essays on the Conceptions of Groups and Identities in America, edited by W. F. Katkin, N.

Landsmen and A. Tyree. Urbana, IL: University of Illinois Press.

Bobo, Lawrence D. 2000. "Reclaiming a Du Boisian Perspective on Racial Attitudes." The Annals of the American Academy of Political and Social Science 568(1):186-202. doi: $10.1177 / 000271620056800114$.

Bobo, Lawrence D., Camille Z. Charles, Maria Kryson, and Alicia D. Simmons. 2012. “The Real Record on Racial Attitudes." Pp. 38-83 in Social Trends in American Life: Findings from the General Social Survey since 1972, edited by P. V. Marsden. Princeton: Princeton University Press.

Bonilla-Silva, Eduardo. 1997. "Rethinking Racism: Toward a Structural Interpretation.” American Sociological Review 62(3):465-80. doi: 10.2307/2657316.

Bonilla-Silva, Eduardo. 2003. Racism without Racists: Color-Blind Racism and the Persistence of Racial Inequality in the United States. Lanham: Rowman \& Littlefield.

Clement, Scott and Emily Guskin. 2019. "For First Time, More Americans Fault Discrimination Than Self-Motivation for White-Black Prosperity Gap." Washington Post (The Fix, March 20, 2019). Washington, DC.

Cramer, Katherine J. 2016. The Politics of Resentment: Rural Consciousness in Wisconsin and the Rise of Scott Walker. Chicago: University of Chicago Press.

Davern, Michael, Rene Bautista, Jeremy Freese, Stephen L. Morgan, and Tom W. Smith. 2021. General Social Survey, 2016-2020 Panel. [Machine-Readable Data File: 1 Datafile (5,125 Logical Records) and 1 Codebook (4,586 Pages)]. Chicago: NORC.

Douds, Kiara and Michael Hout. 2020. "Microaggressions in the United States." Sociological Science 7:528-43. doi: 10.15195/v7.a22.

Du Bois, W. E. B. 1899[1996]. The Philadelphia Negro : A Social Study. Philadelphia: University of Pennsylvania Press. 
Henry, P. J. and David O. Sears. 2002. “The Symbolic Racism 2000 Scale.” Political Psychology 23(2):253-83. doi: 10.1111/0162-895X.00281.

Hout, Michael and Christopher Maggio. 2021. “Immigration, Race \&Amp; Political Polarization." Daedalus 150(2):40-55. doi: 10.1162/daed_a_01845.

Jardina, Ashley. 2019. White Identity Politics. New York: Cambridge University Press.

Kinder, Donald R. and Allison Dale-Riddle. 2012. The End of Race? Obama, 2008, and Racial Politics in America: Yale University Press.

Kinder, Donald R. and Cindy Kam. 2009. Us against Them: Ethnocentric Foundations of American Opinion University of Chicago Press.

Kinder, Donald R. and Lynn M. Sanders. 1996. Divided by Color: Racial Politics and Democratic Ideals. Chicago, Illinois: University of Chicago Press.

Krysan, Maria. 2000. "Prejudice, Politics, and Public Opinion: Understanding the Sources of Racial Policy Attitudes." Annual Review of Sociology 26:135-68.

Morgan, Stephen L. 2017. "A Coding of Social Class for the General Social Survey." GSS Methodological Report No. 125, National Opinion Research Center, Chicago, Illinois.

Morgan, Stephen L. 2020. "Response Rates and Representativeness: A Benchmark Comparison of the General Social Surveys to the American Community Surveys, 2012-2018." GSS Methodological Report No. 131, National Opinion Research Center, Chicago, Illinois.

Morgan, Stephen L. and Jiwon Lee. 2017. "Social Class and Party Identification During the Clinton, Bush, and Obama Presidencies." Sociological Science 4:394-423. doi: 10.15195/v4.a16.

Morgan, Stephen L. and Jiwon Lee. 2019. “Economic Populism and Bandwagon Bigotry: Obama-to-Trump Voters and the Cross Pressures of the 2016 Election." Socius 5:2378023119871119. doi: 10.1177/2378023119871119.

Morgan, Stephen L. and Jiwon Lee. 2020. "Six Alternative Weights That Adjust for Attrition in the 2006-2014 General Social Survey Panels." GSS Methodological Report No. 131, National Opinion Research Center, Chicago, Illinois.

Quillian, Lincoln. 2006. “New Approaches to Understanding Racial Prejudice and Discrimination." Annual Review of Sociology 32(299-328). doi: 10.1146/annurev.soc.32.061604.123132.

Schuman, Howard, Charlotte Steeh, Lawrence D. Bobo, and Maria Krysan. 1998. Racial Attitudes in America: Trends and Interpretations: Harvard University Press.

Sears, David O. 1988. “Symbolic Racism.” Pp. 53-84 in Eliminating Racism: Profiles in Controversy, edited by P. A. Katz and D. A. Taylor. New York: Plenum Press.

Sears, David O. , Jim Sidanius, and Lawrence Bobo, eds. 2000. Racialized Politics: The Debate About Racism in America. Chicago: University of Chicago Press.

Sides, John, Michael Tesler, and Lynn Vavreck. 2018. Identity Crisis: The 2016 Presidential 
Campaign and the Battle for the Meaning of America. Princeton: Princeton University Press.

Smith, Tom W., Michael Davern, Jeremy Freese, and Stephen L. Morgan. 2019. General Social Surveys, 1972-2018 [Machine-Readable Data File: 1 Data File (64,814 Logical Records) and 1 Codebook (3,758 Pp)]. Chicago: NORC.

Sniderman, Paul M. and Philip E. Tetlock. 1986. "Symbolic Racism: Problems of Motive Attribution in Political Analysis." Journal of Social Issues 42(2):129-50. doi: https://doi.org/10.1111/j.1540-4560.1986.tb00229.x.

Tesler, Michael. 2016. Post-Racial or Most-Racial? Race and Politics in the Obama Era. Chicago: University of Chicago Press.

Tesler, Michael and David O. Sears. 2010. Obama's Race: The 2008 Election and the Dream of a PostRacial America. Chicago: The University of Chicago Press.

Tuch, Steven A. and Michael Hughes. 2011. "Whites' Racial Policy Attitudes in the Twenty-First Century: The Continuing Significance of Racial Resentment." The Annals of the American Academy of Political and Social Science 634(1):134-52. doi: 10.1177/0002716210390288. 


\section{Supplement}

In this Supplement, I first offer detail on the data, racial attitude items, and scaling procedures used in the analysis. I then offer additional results that extend the analysis, following the order of results in the main text. All tables are presented at the end of the Supplement.

\section{Data and Weighting}

The sampling design for the 2006-2018 General Social Survey is detailed in Smith et al. (2019). Davern et al. (2021) provide a comprehensive explanation of why and how the 2016 and 2018 GSS respondents were followed up in an unplanned web and phone panel survey in August and September of 2020 (in lieu of conducting a new face-to-face GSS study from April through August of 2020 during the COVID pandemic).

For models in this article that use only data from 2006-2018, I used a slightly modified version of the GSS recommended non-response weight, WTSSNR. First, I scaled the weight so that each year of data would count equally in any model where the years are pooled. Second, I scaled the weights to correct for differential non-response by gender because the GSS, like most surveys, over-represents women. ${ }^{1}$

For models that use data from the 2020 GSS follow-up, I developed a custom weight for the 2020 data. I started with the weights above for the 2016 and 2018 cases. I then used the same strategy explained in Morgan and Lee (2020) to construct attrition-adjusted weights for the respondents who participated in the 2020 survey. ${ }^{2}$ One key change, taken in light of concerns about differential non-response by political party during the 2020 election season, was to enlarge the set of attrition predictors. In addition to all those used for Morgan and Lee (2020), I included base-year party identification and political ideology. I then used an estimated "in scope" probability of participating in the 2020 survey to construct a ratio adjustment to the 2020 base weight (i.e., the scaled version of each respondent's 2016 or 2018 base weight). Finally, I scaled the resulting weights so that the base year 2016 cases would contribute the same amount of information as the base year 2018 cases, following the rationale of Davern et al. (2021; see page 21).

\footnotetext{
${ }^{1}$ All years are scaled so that women are 51.56 percent of the analysis sample, which is a value estimated from the American Community Survey (see Morgan 2020, Table 3). The true population rate is evolving slowly, but not enough to make a difference for adjustment.

${ }^{2}$ Morgan and Lee (2020) show how to generate weights for the GSS panels from 2006-2014. I do not use that panel data in this article, but I adopt the same basic modeling approach to estimate attrition for the 2020 cases.
} 


\section{Racial Attitude Items and Scales}

Table S1 (see tables at the end of this Supplement) presents the wordings of all racial attitude items. The GSS has three randomly assigned questionnaires (Ballots A, B, and C). Most items in the core are present only on two of the ballots, and most of the racial attitudes are on Ballots $\mathrm{A}$ and $\mathrm{B}$. But some items are present on $\mathrm{AC}$ and $\mathrm{BC}$ combinations of ballots. Inclusion in the scales used in the main text is indicated in the final column, and detailed in the next section.

\section{Scale Construction}

The results in Tables 1 and 2 use the raw items detailed in Table S1. However, Tables 3 through 5 use the scales explained in this section.

For Table 3, I introduce two scales based on Tesler (2016). He details two scales in the Online Appendix of his book:

Old Fashioned Racism (GSS): A five-category difference score, which subtracts how favorable or unfavorable white respondents would react to a close relative marrying an AfricanAmerican from how favorable they would feel about their relatives marrying someone of the same race, recoded from 0 (no in-marriage preference) to 1 (strongly favor relative marry a white partner and strongly oppose a black spouse). (Tesler 2016, Online Appendix, Page 2)

Racial Resentment (GSS): An additive index recoded from 0 (least resentful) to 1 (most resentful): The scale was constructed from responses to the following 4 items: 1) Irish, Italian, Jewish and many other minorities overcame prejudice and worked their way up. Blacks should do the same without any special favors. 2) A 3-category variable indicating whether respondents said lack of motivation is or is not a reason for racial inequality (don't know responses are coded to the midpoint. 3) A 3-category variable indicating whether respondents said discrimination is or is not a reason for racial inequality (don't know responses are coded to the midpoint 4) A three-category variable indicating whether respondents rated whites more, less or equally hardworking than blacks on 7-point stereotype scales (don't know responses were coded as 4 for both groups). (Tesler 2016, Online Appendix, Page 3)

For old fashioned racism, I constructed the scale using MARBLK and MARWHT (see Table S1), creating a five-category difference score just as Tesler (2016) did. For racial resentment, I used the same five variables as Tesler, WRKWAYUP, RACDIF1, RACDIF4, and the difference between WORKWHTS and WORKBLKS (see Table S1). However, for consistency with the other scales, detailed below, I used a graded response IRT model for scale construction, after which I standardized the scale to have a variance of 1 over the full 2006-2020 sample.

For Table 4, I analyzed the racial resentment scale again, as well as two new scales that correspond to the differentiation of substance across Tables 1 and 2, one for prejudice and 
bigotry and one for opposition to compensatory support. The scale for prejudice and bigotry includes five items from Tables 1: INTLWHTS, INTLBLKS, MARBLK, RACDIF2, and RACDIF4 (see Table S1 for wordings). The scale for opposition to compensatory support includes all four items from Table 2: AFFRMACT, WRKWAYUP, HELPBLK, and DISCAFF (again, see Table S1). As for my version of Tesler's racial resentment scale, I used graded response IRT models for scale construction, after which I standardized each scale to have a variance of 1 over the full 2006-2020 sample.

To check for the robustness of results on period effects, I estimate additional models below. For Table S11, I expand the scale for prejudice and bigotry to 11 items, adding RACDIF1, RACDIF3, MARASIAN, MARHISP, LIVEBLKS, and LETNIN1A (see Table S1). I also drop two items from the scale for opposition to compensatory support, so that it includes only AFFRMACT and WRKWAYUP. Finally, in Table S12, I offer period-effect estimates for most of the indicators separately. The results are all consistent, as noted in the next section.

\section{Supplemental Results}

Racial resentment regressions. Tables S2-S4 extend the analysis reported in the main text in Table 3. Rather than restrict the analysis to the 2010 through 2018 GSS data, the results in in these three tables vary the years that are included. Overall, the findings are similar. As years are added, the results for party identification strengthen. The support is slightly weaker for the claims in the main text for the models focused solely on retrospective votes for 2012 and 2016 in Table S4 (reported, respectively, in 2014 and 2018). The weakening may simply be the result of greater relative sampling error because of the smaller sample size for those models, but it could also be the case that the increase is clearer over a larger number of years because the trend is a general one, not one that is narrowly revealed by a targeted comparison of vote choices for the 2012 to 2016 general elections.

Models for change, with a full explanation of the strategy for adjusting for baseline change through cohort replacement. In this section, I explain the first 3 steps of the analysis design that I adopt to model change in racial attitudes. I use Tesler's racial resentment scale in order to demonstrate the steps. I also offer results for a wider range of race-ethnic groups than modeled for the results in the main text. After detailing the approach with racial resentment, I consider alternative outcomes.

The first three columns of Table S5 present alternative baseline demographic models for change in the racial resentment of white respondents from 2006 to 2012. The next three columns present models for Hispanic respondents to provide a point of comparison. Table S6, below, provides the same analysis for the other two race-ethnic groups analyzed for Tables 1 and 2. I will provide the full explanation for white respondents, as they are the main focus of the analysis reported in the main text, but the strategy deployed in Tables S5 and S6 is the same for all four groups. 
Model 1 includes indicators for gender, educational attainment, and social class. Focusing only on white respondents for now, the associations show that education and class both predict racial resentment, as complements to each other. Gender has little or no association with racial resentment, net of education and class.

Model 2 adds a regressor for birth cohort, specified as the year in which each respondent was born (centered on 1971 and divided by 10 for interpretability). The negative coefficient suggests that more recent cohorts have net lower levels of racial resentment. A two-decade difference in birth year is associated with a net difference of 0.144 standard deviations in racial resentment.

While such net between-cohort characterizations are correct interpretations, Model 2 was not specified in an attempt to generate a best-fitting representation of how racial resentment varies with the full cohort structure of the GSS from 2006 to 2012. That full predictive surface is surely not captured sufficiently well by a linear-in-birth-year regressor (with a coefficient estimated alongside others for gender, educational attainment, and class). Instead, the goal of Model 2 is to model the changes across the years of observation from 2006 through 2012 that are due to cohort replacement, using a regressor that can be extrapolated to generate a counterfactual fit for the 2014-2020 interval.

Thus, the negative coefficient for the cohort predictor should not be over-interpreted. The specification implies that the outcome, racial resentment, is changing linearly, on average, in response to the shifting composition of birth cohorts, which push the average birth year higher over time. The cohort replacement shift can be thought of as an encoding of all cohort differences, as they pass through the observation interval. For example, in each year of observation, a higher percentage of the sample is composed of individuals whose formative early adulthood years occurred after the most prominent events of the civil rights movement, and Model 2 shows that racial resentment declines linearly as these individuals become a larger overall percentage of the GSS sample.

Model 3 then shows that this strategy works sufficiently well for white respondents. To the specification for Model 2, I add the year of GSS observation as a linear term. The resulting coefficient has little or no net association with racial resentment when specified alongside gender, education, class, and birth year. Moreover, the negative birth-year coefficient is reduced only to a trivial extent. Thus, Model 3 suggests that Model 2 alone captures the underlying trend between 2006 and 2012 sufficiently well. And that change, as shown below, can form the basis for a counterfactual trend between 2014 and 2020, as if nothing more than upgrading in education, class, and cohort replacement were occurring. ${ }^{3}$

\footnotetext{
${ }^{3}$ For readers familiar with the identification challenges associated with the age-period-cohort accounting model, the claim here is that for this observation interval from 2006 to 2012, the period effect is ignorable once a cohort effect has been specified (and in this case, a very simple linear-in-birth-year cohort effect). Moreover, I take the epidemiological position on cohort analysis that cohort effects carry forward entangled past age and period effects into the observation interval.
} 
The equivalent models for Hispanics in Table S5 and for non-Hispanic blacks in Table S6 provide side support for this modeling approach. While the pattern of associations for education and class is somewhat different for these groups, and while the cohort terms suggest different patterns of net change beyond shifts in education and class, the year of observation coefficients in Model 3 again have little or no net predictive power.

Finally, the year of observation coefficient for the last set of models for Asians in Table S6 is more negative. While I expect that this is due to chance variability because of the many coefficients fit for a smaller sample, the results for Asian respondents may provide some suggestive evidence for a period effect between 2006 and 2012 for Asians that cannot be captured by cohort replacement or by shifts in education and class position. It is possible that additional regressors for ethnic origins, resulting from variation in immigration patterns, need to be fit in order to account for what appears to be genuine period variation.

Table S7 then presents models of change in racial resentment for the full 2006 to 2020 interval, limited to white respondents only. The first column presents a model of raw change, which fits indicators for each GSS year, deviated from 2012, to the raw racial resentment scale. These "raw" results are the same ones presented in Table 4 in the main text. As discussed in the main text, the changes shown for the indicators for 2014, 2016, and 2018 indicate that racial resentment declined over these six years, on average, by more than one third of a standard deviation.

Note also that for this model a coefficient is fit for 2020, and it suggests a modest further continuation in the decline of racial resentment. This change is discussed briefly in the main text, and, in this Supplement, I provide a more complete explanation.

As noted above in the Data section, the GSS project launched an unanticipated follow-up study in 2020, which was made necessary because the COVID pandemic disrupted the plan to conduct a fresh cross-sectional survey through face-to-face interviewing in spring and summer of 2020. Instead, respondents who were first sampled in 2016 and 2018 were asked to complete a follow-up survey by phone or web, covering all core items from the GSS, including the racial attitudes in Table S1.

Most of the data collection for the 2020 follow-up was completed in the late summer and early fall. Thus, we have available a unique set of observations available for 2020, and for the models in Table S7 these observations are added to the sample for analysis. The 2020 observations for individuals from the original 2016 and 2018 cross-sectional surveys are weighted for analysis to (a) adjust for non-random attrition from the respective base year and (b) so that the 2020 estimates are based on variation that is equally balanced across respondents sampled in 2016 and 2018 (see above for an explanation of the weight construction). 
The inclusion of the 2020 observations in the first model in Table S7 does not change any of the coefficients for the other years, since all years are deviated from 2012 and the inclusion of 2020 observations are irrelevant to these comparisons. Thus, the inclusion of the 2020 observations is best seen as a separable augmentation of the model, which provides additional evidence of a further decline in racial resentment among white respondents in 2020.

The next three columns of Table S7 then have the same specification of year predictors but for a residualized version of the racial resentment scale. I subtracted predicted values generated by the coefficients of Models 1 through 3 in Table S5 from the raw racial resentment scale. For 2006 through 2012, the predicted values are those values that are directly fit by the model. For 2014 through 2020, the predicted values are extrapolated counterfactual values (i.e., the dot product of the coefficients from Models 1 through 3 with the vector of predictors observed in years 2014 through 2020). Residualization with the estimated parameters of Model 2 is the most sensible, as explained above, and thus the residualizations provided by Models 1 and 3 are provided for comparison only. The Model 2 results show that net deviations of racial resentment before 2012 are negligible, relative to the underlying change model that has been directly fit for these years. The motivation of the model is to enable an examination of the decline in racial resentment after 2012. As can be seen in a comparison of the coefficients from the first and third columns, most of the raw change after 2012 remains unaccounted for. Accordingly, the net change after residualization with Model 2 can be interpreted as an emergent period effect that cumulated from 2014 through 2020 (i.e., above and beyond the baseline change that is attributable to cohort replacement).

The three final columns of Table S7 repeat the same analysis, dropping respondents in 2016 and 2018 who did not participate in the 2020 follow-up survey. The weights are adjusted accordingly (by applying the attrition weights to the 2016 and 2018 observations, rather than only the 2020 observations). The effective sample size declines, and only the 2016 and 2018 coefficients have scope to change. And they change only very slightly. This model gives evidence of an average within-person decline in racial resentment by 2020 for respondents sampled in both 2016 and 2018 and suggests that the models in the prior three columns are reasonable because the attrition weighting is effective more generally.

Table 4 in the main text displays the results in the first and third columns in Table S7. Tables S8 - S10 repeat the analysis in Table S7 for the additional three race-ethnic groups and thus extend the results presented in the main text. After 2012, movement is generally toward the racial sympathy pole for all three groups, but the extent of that movement depends on whether residualization with Model 2 or Model 3 is utilized. For the same reason, movement before 2012 is also more heterogeneous. Overall, the declines in racial resentment for these three groups are also consistent with my favored interpretation: a broad cumulative response to the activism associated with the movement for racial justice.

Table 4 in the main text adds two additional scales as outcomes, with the underlying residualization explained above used to structure analogous models. Table S11 presents the 
same results from Table 4 for these two scales, along with alternative versions of those scales (detailed above). The results are generally the same, and I chose to use the versions of the scales in Table 4 in the main text because they were (a) most consistent with theories about anti-black racism and (b) have comparable numbers of items as the racial resentment scale. Thus, they are targeted on the same domain and generated by similar amounts of between-respondent variation.

Of course, none of these scales may be convincing to the reader. Accordingly, I provide in Table S12 indicator-specific models for period effects. The same patterns are present, and one value of the indicator-specific models are the metric coefficients that show absolute change.

Finally, Table S13 is a direct analog to Table 5 in the main text, but it drops the 2006 and 2008 data and also adds the 2020 follow-up observations. The results are very similar, as expected, based on the similarity shown earlier in comparisons to Table 3. 
Table S1. Wording and response options for items on the GSS from 2006 to 2020 that measure racial attitudes toward African-Americans and black people (in order on questionnaire)

\begin{tabular}{|c|c|c|c|c|}
\hline GSS variable & Question wording & $\begin{array}{l}\text { Response } \\
\text { categories }\end{array}$ & Ballots & Scale inclusion \\
\hline \multirow[t]{2}{*}{$\begin{array}{l}\text { Attribution of } \\
\text { black-white } \\
\text { differences: }\end{array}$} & \multicolumn{2}{|l|}{$\begin{array}{l}\text { On the average blacks have worse } \\
\text { jobs, income, and housing than } \\
\text { white people. }\end{array}$} & & \\
\hline & \multicolumn{2}{|l|}{ Do you think these differences are ... } & & \\
\hline RACDIF1 & Mainly due to discrimination? & $\begin{array}{l}\text { Yes } \\
\text { No }\end{array}$ & $\mathrm{AB}$ & RR and PB 11-item \\
\hline RACDIF2 & $\begin{array}{l}\text { Because most blacks have less in- } \\
\text { born ability to learn? }\end{array}$ & $\begin{array}{l}\text { Yes } \\
\text { No }\end{array}$ & “ & $\begin{array}{l}\text { PB 5-item and PB 11- } \\
\text { item }\end{array}$ \\
\hline RACDIF3 & $\begin{array}{l}\text { Because most blacks don't have the } \\
\text { chance for education that it takes to } \\
\text { rise out of poverty? }\end{array}$ & $\begin{array}{l}\text { Yes } \\
\text { No }\end{array}$ & “ & PB 11-item \\
\hline RACDIF4 & $\begin{array}{l}\text { Because most blacks just don't have } \\
\text { the motivation or will power to pull } \\
\text { themselves up out of poverty? }\end{array}$ & $\begin{array}{l}\text { Yes } \\
\text { No }\end{array}$ & “ & $\begin{array}{l}\text { RR, PB 5-item, and PB } \\
\text { 11-item }\end{array}$ \\
\hline $\begin{array}{l}\text { Support for } \\
\text { affirmative } \\
\text { action: }\end{array}$ & $\begin{array}{l}\text { Some people say that because of past } \\
\text { discrimination, blacks should be } \\
\text { given preference in hiring and } \\
\text { promotion. Others say that such } \\
\text { preference in hiring and promotion } \\
\text { of blacks is wrong because it } \\
\text { discriminates against Whites. }\end{array}$ & & & \\
\hline AFFRMACT & $\begin{array}{l}\text { What about your opinion - are you } \\
\text { for or against preferential hiring and } \\
\text { promotion of blacks? }\end{array}$ & $\begin{array}{l}\text { Strongly favor } \\
\text { Favor } \\
\text { Oppose } \\
\text { Strongly oppose }\end{array}$ & $\mathrm{AB}$ & $\begin{array}{l}\text { OCS 2-item and OCS } \\
\text { 4-item }\end{array}$ \\
\hline \multicolumn{5}{|c|}{$\begin{array}{l}\text { Favors needed to } \\
\text { overcome } \\
\text { prejudice: }\end{array}$} \\
\hline \multirow[t]{2}{*}{ WRKWAYUP } & $\begin{array}{l}\text { Do you agree strongly, agree } \\
\text { somewhat, neither agree nor } \\
\text { disagree, disagree somewhat, or } \\
\text { disagree strongly with the following } \\
\text { statement: }\end{array}$ & $\begin{array}{l}\text { Agree strongly } \\
\text { Agree somewhat } \\
\text { Neither agree nor } \\
\text { disagree } \\
\text { Disagree } \\
\text { somewhat }\end{array}$ & “ & $\begin{array}{l}\text { RR, OCS 2-item, and } \\
\text { OCS 4-item }\end{array}$ \\
\hline & $\begin{array}{l}\text { Irish, Italians, Jewish and many } \\
\text { other minorities overcame prejudice } \\
\text { and worked their way up. Blacks }\end{array}$ & Disagree strongly & & \\
\hline
\end{tabular}


should do the same without special favors.

\section{Believe in \\ bigoted \\ stereotypes:}

INTLWHTS and

INTLBLKS

(preceded by parallel items for a rich - poor scale in order to introduce the response scales)

WORKWHTS

and

WORKBLKS

Residential
integration:

LIVEBLKS

Now I have some questions about is a seven-point scale on which the characteristics of people in a group can be rated.

A score of 1 means that you think are 'unintelligent.' A score of 7 means that you think almost A score of 4 means that you think that the group is not towards one end or the other, and of course you that comes closest to where you think people in the group stand.

Where would you rate whites in general on this scale?

Blacks? if people in the group tend to be hard-working or if they tend to be lazy.

Where would you rate whites in general on this scale?

Blacks?

Now I'm going to ask you about different types of contact with various groups of people. In each situation would you please tell me different groups in our society. Here almost all of the people in the group everyone in the group is 'intelligent.' may choose any number in between

The second set of characteristics asks whether you would be very much in favor of it happening, somewhat in favor, neither in favor nor opposed to it happening, somewhat opposed, or very much opposed to it happening.
Two 7-point scales from 1 for unintelligent to 7 for intelligent, coded as

INTLWHTS

minus

INTLBLKS
$\mathrm{AB}$

PB 5-item and PB 11item

\section{Two 7-point \\ $\mathrm{AB} \quad \mathrm{RR}$ hard working to 7 for lazy, coded as WORKWHTS \\ minus WORKBLKS}

Very much in favor Somewhat in favor Neither in favor nor opposed

Somewhat opposed

Living in a neighborhood where half of your neighbors are Blacks?
Very much opposed 
Intermarriage: Now I'm going to ask you about another type of contact with various groups of people.

MARWHT What about having a close relative marry a white person? Would you be very in favor of it happening, somewhat in favor, neither in favor nor opposed to it happening, somewhat opposed, or very opposed to it happening?

MARBLK

MARASIAN

MARHISP

Reverse

discrimination:

DISCAFF

What do you think the chances are these days that a white person won't get a job or promotion while an equally or less qualified black person gets one instead? Is this very likely, somewhat likely, or not very likely to happen these days?

\section{Support for immigration:}

LETIN1A

Government assistance:

HELPBLK

What about having a close relative marry a black person? immigrants to America nowadays should be ...?
Very much in favor

Somewhat in

favor

Neither in favor nor opposed

Somewhat

opposed

Very much

opposed

Very likely

Somewhat likely

Not very likely

Increased a lot

Increased a little

Remain the same as it is

Reduced a little

Reduced a lot

5-point scale from "strongly agree that the government is obligated to help blacks" to "strongly agree that the
Please look at the hand card. Some people think that blacks have been discriminated against for so long that the government has a special obligation to help improve their living standards. Others believe that the government should not be giving special treatment to blacks.

\section{AB PB 5-item and PB 11-} item

PB 11-item

PB 11-item

AC OCS 4-item

\section{BC OCS 4-item}


Where would you place yourself on this scale, or haven't you made up your mind on this? government

shouldn't give

special

treatment"

Notes: The scale acronyms are RR fop racial resentment, PB for prejudice and bigotry, and OCS for opposition to compensatory support. 
Table S2 (for comparison with Table 3). Results from twelve least squares models of change in the net predictive power of measures of old-fashioned racism and racial resentment for white-only, non-

Hispanic respondents (for 2006 - 2018, rather than 2010 - 2018, as in Table 3)

\begin{tabular}{|c|c|c|c|c|}
\hline \multirow[b]{3}{*}{ Predictor (in separate models) } & \multicolumn{2}{|c|}{ Outcome: } & \multicolumn{2}{|c|}{ Outcome: } \\
\hline & \multicolumn{2}{|c|}{$\begin{array}{l}\text { Party Identification Scale } \\
\text { (1 for Strong Democrat } \\
\text { to } 7 \text { for Strong Republican) }\end{array}$} & \multicolumn{2}{|c|}{$\begin{array}{l}\text { Voted for Republican } \\
\text { Presidential Candidate } \\
\quad(1=\text { Yes, } 0=\mathrm{No})\end{array}$} \\
\hline & $\begin{array}{l}\text { First period } \\
\text { regression } \\
\text { coefficient } \\
(2006-2014) \\
\end{array}$ & $\begin{array}{c}\text { Difference for } \\
\text { second period } \\
(2016-2018) \\
\end{array}$ & $\begin{array}{l}\text { First period } \\
\text { regression } \\
\text { coefficient } \\
(2006-2014) \\
\end{array}$ & $\begin{array}{c}\text { Difference for } \\
\text { second period } \\
(2016-2018) \\
\end{array}$ \\
\hline $\begin{array}{l}\text { Old-fashioned racism } \\
\text { ( } 5 \text { category scale, MARWHT and } \\
\text { MARBLK) }\end{array}$ & $\begin{array}{c}0.184 \\
(0.028)\end{array}$ & $\begin{array}{c}0.070 \\
(0.053)\end{array}$ & $\begin{array}{c}0.069 \\
(0.007)\end{array}$ & $\begin{array}{l}-0.009 \\
(0.023)\end{array}$ \\
\hline $\begin{array}{l}\text { Racial resentment scale } \\
\text { (indicators below) }\end{array}$ & $\begin{array}{c}0.537 \\
(0.036)\end{array}$ & $\begin{array}{c}0.247 \\
(0.057)\end{array}$ & $\begin{array}{c}0.173 \\
(0.010)\end{array}$ & $\begin{array}{c}0.075 \\
(0.019)\end{array}$ \\
\hline $\begin{array}{l}\text { Items in racial resentment scale: } \\
\text { Discrimination responsible } \\
\text { for black-white differences } \\
\text { (RACDIF1) }\end{array}$ & $\begin{array}{l}-0.849 \\
(0.078)\end{array}$ & $\begin{array}{l}-0.499 \\
(0.139)\end{array}$ & $\begin{array}{l}-0.263 \\
(0.024)\end{array}$ & $\begin{array}{l}-0.190 \\
(0.052)\end{array}$ \\
\hline $\begin{array}{l}\text { Lack of motivation among } \\
\text { blacks responsible (RACDIF4) }\end{array}$ & $\begin{array}{c}0.582 \\
(0.073)\end{array}$ & $\begin{array}{c}0.399 \\
(0.126)\end{array}$ & $\begin{array}{c}0.208 \\
(0.022)\end{array}$ & $\begin{array}{c}0.172 \\
(0.047)\end{array}$ \\
\hline $\begin{array}{l}\text { No special favors for blacks } \\
\text { (WRKWAYUP reversed) }\end{array}$ & $\begin{array}{c}0.421 \\
(0.030)\end{array}$ & $\begin{array}{c}0.152 \\
(0.047)\end{array}$ & $\begin{array}{c}0.131 \\
(0.009)\end{array}$ & $\begin{array}{c}0.038 \\
(0.017)\end{array}$ \\
\hline $\begin{array}{l}\text { Blacks less hard working and } \\
\text { more lazy than whites } \\
\text { (WORKBLKS, WORKWHTS) }\end{array}$ & $\begin{array}{c}0.095 \\
(0.028)\end{array}$ & $\begin{array}{c}0.129 \\
(0.055)\end{array}$ & $\begin{array}{c}0.046 \\
(0.008)\end{array}$ & $\begin{array}{c}0.041 \\
(0.022)\end{array}$ \\
\hline
\end{tabular}


Table S3 (for comparison with Table 3). Results from twelve least squares models of change in the net predictive power of measures of old-fashioned racism and racial resentment for white-only, non-

Hispanic respondents (for 2010 - 2020, rather than 2010 - 2018, as in Table 3)

First period

Predictor (in separate models)

Old-fashioned racism

(5 category scale, MARWHT and MARBLK)

Racial resentment scale

(indicators below)

Items in racial resentment scale: Discrimination responsible for black-white differences (RACDIF1)

Lack of motivation among blacks responsible (RACDIF4)

No special favors for blacks (WRKWAYUP reversed)

Blacks less hard working and more lazy than whites (WORKBLKS, WORKWHTS)
Outcome:

Party Identification Scale

(1 for Strong Democrat

to 7 for Strong Republican) regression coefficient

Outcome:

Voted for Republican

Presidential Candidate $(1=$ Yes, $0=$ No)

First period regression Difference for coefficient second period (2010-2014) (2016-2020) (2010-2014) (2016-2020)

$\begin{array}{cccc}0.241 & -0.005 & 0.080 & -0.031 \\ (0.042) & (0.062) & (0.009) & (0.018)\end{array}$

0.594

(0.047)

0.295

0.196

0.075

(0.063)

(0.012)

(0.016)

$-0.918$

$-0.786$

$-0.297$

$-0.235$

(0.097)

(0.141)

(0.031)

(0.044)

$\begin{array}{cccc}0.704 & 0.419 & 0.238 & 0.154 \\ (0.095) & (0.144) & (0.029) & (0.049) \\ & & & \\ 0.455 & 0.206 & 0.150 & 0.049 \\ (0.035) & (0.047) & (0.010) & (0.014) \\ & & & \\ 0.117 & 0.151 & 0.051 & 0.065 \\ (0.038) & (0.061) & (0.011) & (0.016)\end{array}$


Table S4 (for comparison with Table 3). Results from twelve least squares models of change in the net predictive power of measures of old-fashioned racism and racial resentment for white-only, non-

Hispanic respondents (for 2014 and 2018, rather than 2010 - 2018, as in Table 3)

First period

Predictor (in separate models)

Old-fashioned racism

(5 category scale, MARWHT and MARBLK)

Racial resentment scale

(indicators below)

Items in racial resentment scale: Discrimination responsible for black-white differences (RACDIF1)

Lack of motivation among blacks responsible (RACDIF4)

No special favors for blacks (WRKWAYUP reversed)

Blacks less hard working and more lazy than whites (WORKBLKS, WORKWHTS)
Outcome:

Party Identification Scale

(1 for Strong Democrat

to 7 for Strong Republican) regression coefficient

Outcome:

Voted for Republican

Presidential Candidate

$$
(1=\text { Yes, } 0=\text { No })
$$

First period regression Difference for coefficient second period (2010-2014) second period (2016-2020) (2010-2014) (2016-2020)

$\begin{array}{cccc}0.286 & -0.073 & 0.105 & -0.047 \\ (0.061) & (0.087) & (0.013) & (0.023)\end{array}$

$\begin{array}{cccc}0.605 & 0.234 & 0.228 & 0.019 \\ (0.081) & (0.098) & (0.018) & (0.024)\end{array}$

$\begin{array}{llll}-1.116 & -0.349 & -0.337 & -0.112 \\ (0.144) & (0.214) & (0.043) & (0.059)\end{array}$

0.634

0.271

0.280

0.089

$(0.149)$

(0.207)

(0.043)

(0.057)

0.462

0.159

0.162

0.007

(0.064)

(0.080)

(0.016)

(0.021)

0.152

0.091

0.084

$<0.001$

(0.055)

(0.092)

(0.017)

(0.025) 
Table S5. Three least squares models for potential residualization of the underlying change in the racial resentment scale for white-only non-Hispanic respondents and Hispanic, non-black respondents, 2006-2012 pooled sample

White-only, non-Hispanic Hispanic, non-black $\begin{array}{llllll}\text { Model } 1 & \text { Model } 2 & \text { Model } 3 & \text { Model } 1 & \text { Model } 2 & \text { Model } 3\end{array}$

Gender (Male reference):

Female

$\begin{array}{cccccc}0.005 & -0.012 & -0.012 & -0.034 & -0.050 & -0.052 \\ (0.041) & (0.040) & (0.040) & (0.115) & (0.112) & (0.110)\end{array}$

\section{Educational attainment (HS diploma \\ ref.):}

No HS diploma

$\begin{array}{llllll}-0.049 & -0.090 & -0.089 & -0.118 & -0.132 & -0.135 \\ (0.066) & (0.067) & (0.067) & (0.104) & (0.101) & (0.104)\end{array}$

Some college

$\begin{array}{llllll}-0.064 & -0.054 & -0.056 & -0.555 & -0.561 & -0.567 \\ (0.060) & (0.062) & (0.062) & (0.374) & (0.376) & (0.388)\end{array}$

Bachelor's degree

$\begin{array}{llllll}-0.411 & -0.395 & -0.395 & -0.405 & -0.404 & -0.407 \\ (0.049) & (0.049) & (0.048) & (0.304) & (0.299) & (0.300)\end{array}$

Graduate degree

$\begin{array}{llllll}-0.632 & -0.654 & -0.655 & -1.065 & -1.060 & -1.046 \\ (0.075) & (0.074) & (0.075) & (0.277) & (0.276) & (0.274)\end{array}$

EGP social class (Class VIIa ref.):

\begin{tabular}{|c|c|c|c|c|c|c|}
\hline I & $\begin{array}{l}-0.025 \\
(0.086)\end{array}$ & $\begin{array}{l}-0.061 \\
(0.085)\end{array}$ & $\begin{array}{l}-0.060 \\
(0.085)\end{array}$ & $\begin{array}{l}-0.051 \\
(0.354)\end{array}$ & $\begin{array}{l}-0.102 \\
(0.356)\end{array}$ & $\begin{array}{l}-0.104 \\
(0.361)\end{array}$ \\
\hline II & $\begin{array}{l}-0.097 \\
(0.074)\end{array}$ & $\begin{array}{l}-0.111 \\
(0.073)\end{array}$ & $\begin{array}{l}-0.109 \\
(0.073)\end{array}$ & $\begin{array}{l}-0.096 \\
(0.229)\end{array}$ & $\begin{array}{l}-0.107 \\
(0.225)\end{array}$ & $\begin{array}{l}-0.112 \\
(0.224)\end{array}$ \\
\hline IIIa & $\begin{array}{c}0.030 \\
(0.070)\end{array}$ & $\begin{array}{c}0.019 \\
(0.070)\end{array}$ & $\begin{array}{c}0.019 \\
(0.070)\end{array}$ & $\begin{array}{c}0.096 \\
(0.213)\end{array}$ & $\begin{array}{c}0.108 \\
(0.213)\end{array}$ & $\begin{array}{c}0.103 \\
(0.212)\end{array}$ \\
\hline IIIb & $\begin{array}{l}-0.147 \\
(0.074)\end{array}$ & $\begin{array}{l}-0.087 \\
(0.074)\end{array}$ & $\begin{array}{l}-0.087 \\
(0.074)\end{array}$ & $\begin{array}{l}-0.171 \\
(0.143)\end{array}$ & $\begin{array}{l}-0.156 \\
(0.139)\end{array}$ & $\begin{array}{l}-0.157 \\
(0.140)\end{array}$ \\
\hline IVab & $\begin{array}{c}0.042 \\
(0.078)\end{array}$ & $\begin{array}{c}0.011 \\
(0.078)\end{array}$ & $\begin{array}{c}0.012 \\
(0.078)\end{array}$ & $\begin{array}{c}0.300 \\
(0.217)\end{array}$ & $\begin{array}{c}0.280 \\
(0.218)\end{array}$ & $\begin{array}{c}0.273 \\
(0.215)\end{array}$ \\
\hline $\mathrm{IVC}_{\mathrm{C}}$ & 0.155 & 0.076 & 0.073 & 0.023 & 0.046 & 0.064 \\
\hline
\end{tabular}




\begin{tabular}{|c|c|c|c|c|c|c|}
\hline & $(0.195)$ & $(0.181)$ & $(0.181)$ & $(0.092)$ & (0.095) & $(0.112)$ \\
\hline V & $\begin{array}{c}0.115 \\
(0.088)\end{array}$ & $\begin{array}{c}0.111 \\
(0.089)\end{array}$ & $\begin{array}{c}0.111 \\
(0.089)\end{array}$ & $\begin{array}{l}-0.083 \\
(0.237)\end{array}$ & $\begin{array}{l}-0.113 \\
(0.238)\end{array}$ & $\begin{array}{l}-0.119 \\
(0.238)\end{array}$ \\
\hline VI & $\begin{array}{c}0.252 \\
(0.093)\end{array}$ & $\begin{array}{c}0.233 \\
(0.094)\end{array}$ & $\begin{array}{c}0.233 \\
(0.094)\end{array}$ & $\begin{array}{c}0.418 \\
(0.157)\end{array}$ & $\begin{array}{c}0.404 \\
(0.163)\end{array}$ & $\begin{array}{c}0.401 \\
(0.162)\end{array}$ \\
\hline VIIb & $\begin{array}{l}-0.144 \\
(0.274)\end{array}$ & $\begin{array}{l}-0.146 \\
(0.271)\end{array}$ & $\begin{array}{l}-0.149 \\
(0.271)\end{array}$ & $\begin{array}{l}-0.085 \\
(0.226)\end{array}$ & $\begin{array}{l}-0.123 \\
(0.228)\end{array}$ & $\begin{array}{l}-0.136 \\
(0.225)\end{array}$ \\
\hline Military & $\begin{array}{l}-0.127 \\
(0.143)\end{array}$ & $\begin{array}{l}-0.155 \\
(0.144)\end{array}$ & $\begin{array}{l}-0.149 \\
(0.146)\end{array}$ & $\begin{array}{c}0.171 \\
(0.588)\end{array}$ & $\begin{array}{c}0.114 \\
(0.574)\end{array}$ & $\begin{array}{c}0.107 \\
(0.586)\end{array}$ \\
\hline $\begin{array}{l}\text { Birth cohort, centered on 1971, in } \\
\text { decades }\end{array}$ & & $\begin{array}{l}-0.072 \\
(0.010)\end{array}$ & $\begin{array}{l}-0.071 \\
(0.010)\end{array}$ & & $\begin{array}{l}-0.044 \\
(0.031)\end{array}$ & $\begin{array}{l}-0.042 \\
(0.032)\end{array}$ \\
\hline Year & & & $\begin{array}{l}-0.006 \\
(0.009)\end{array}$ & & & $\begin{array}{l}-0.013 \\
(0.027)\end{array}$ \\
\hline Intercept & $\begin{array}{c}0.390 \\
(0.051)\end{array}$ & $\begin{array}{c}0.331 \\
(0.054)\end{array}$ & $\begin{array}{c}0.302 \\
(0.073)\end{array}$ & $\begin{array}{c}0.407 \\
(0.135)\end{array}$ & $\begin{array}{c}0.417 \\
(0.133)\end{array}$ & $\begin{array}{c}0.356 \\
(0.196)\end{array}$ \\
\hline $\begin{array}{l}\text { R-squared } \\
N\end{array}$ & $\begin{array}{c}0.082 \\
3993\end{array}$ & $\begin{array}{c}0.100 \\
3993\end{array}$ & $\begin{array}{c}0.100 \\
3993\end{array}$ & $\begin{array}{c}0.097 \\
709\end{array}$ & $\begin{array}{c}0.102 \\
709\end{array}$ & $\begin{array}{c}0.103 \\
709\end{array}$ \\
\hline
\end{tabular}

Notes: A small amount of missing data on educational attainment was imputed with random forest imputation. A comparatively large amount of missing data for EGP class was imputed as well, primarily for respondents who reported never having had an occupation. Thus, the EGP class for such respondents is a "what if" class, assuming that these individuals' EGP classes can be predicted reasonably from the joint distribution of observed EGP class with race, gender, education, cohort, and other observed variables in the imputation regime. 
Table S6. Three least squares models for potential residualization of the underlying change in the racial resentment scale for black-only non-Hispanic respondents and Asian-only non-Hispanic respondents, 20062012 pooled sample

Black-only, non-Hispanic Asian-only, non-Hispanic $\begin{array}{llllll}\text { Model } 1 & \text { Model } 2 & \text { Model } 3 & \text { Model } 1 & \text { Model } 2 & \text { Model } 3\end{array}$

\section{Gender (Male reference):}

Female

$\begin{array}{llllll}-0.081 & -0.059 & -0.066 & -0.037 & -0.037 & -0.053 \\ (0.102) & (0.106) & (0.106) & (0.172) & (0.170) & (0.166)\end{array}$

\section{Educational attainment (HS diploma} ref.):

No HS diploma

$\begin{array}{cccccc}0.089 & 0.119 & 0.118 & 0.252 & 0.257 & 0.250 \\ (0.149) & (0.149) & (0.149) & (0.326) & (0.328) & (0.280)\end{array}$

Some college

$\begin{array}{cccccc}-0.005 & -0.002 & -0.001 & 0.059 & 0.062 & 0.142 \\ (0.201) & (0.200) & (0.197) & (0.588) & (0.584) & (0.439)\end{array}$

Bachelor's degree

$\begin{array}{cccccc}-0.347 & -0.338 & -0.355 & 0.229 & 0.238 & 0.199 \\ (0.219) & (0.214) & (0.215) & (0.274) & (0.293) & (0.291)\end{array}$

Graduate degree

$\begin{array}{cccccc}-0.560 & -0.513 & -0.547 & 0.580 & 0.592 & 0.603 \\ (0.273) & (0.264) & (0.261) & (0.354) & (0.358) & (0.328)\end{array}$

\section{EGP social class (Class VIIa ref.):}

\begin{tabular}{|c|c|c|c|c|c|c|}
\hline I & $\begin{array}{l}-0.365 \\
(0.360)\end{array}$ & $\begin{array}{l}-0.355 \\
(0.360)\end{array}$ & $\begin{array}{l}-0.344 \\
(0.354)\end{array}$ & $\begin{array}{l}-0.660 \\
(0.282)\end{array}$ & $\begin{array}{l}-0.668 \\
(0.272)\end{array}$ & $\begin{array}{l}-0.640 \\
(0.305)\end{array}$ \\
\hline II & $\begin{array}{l}-0.263 \\
(0.280)\end{array}$ & $\begin{array}{l}-0.263 \\
(0.287)\end{array}$ & $\begin{array}{l}-0.249 \\
(0.289)\end{array}$ & $\begin{array}{l}-0.569 \\
(0.309)\end{array}$ & $\begin{array}{l}-0.571 \\
(0.305)\end{array}$ & $\begin{array}{l}-0.556 \\
(0.347)\end{array}$ \\
\hline IIIa & $\begin{array}{l}-0.077 \\
(0.183)\end{array}$ & $\begin{array}{l}-0.089 \\
(0.184)\end{array}$ & $\begin{array}{l}-0.079 \\
(0.185)\end{array}$ & $\begin{array}{l}-0.236 \\
(0.186)\end{array}$ & $\begin{array}{l}-0.239 \\
(0.179)\end{array}$ & $\begin{array}{l}-0.233 \\
(0.225)\end{array}$ \\
\hline $\mathrm{IIIl}$ & $\begin{array}{c}0.059 \\
(0.146)\end{array}$ & $\begin{array}{c}0.025 \\
(0.152)\end{array}$ & $\begin{array}{c}0.029 \\
(0.152)\end{array}$ & $\begin{array}{l}-0.181 \\
(0.299)\end{array}$ & $\begin{array}{l}-0.186 \\
(0.313)\end{array}$ & $\begin{array}{l}-0.207 \\
(0.351)\end{array}$ \\
\hline IVab & $\begin{array}{c}0.004 \\
(0.201)\end{array}$ & $\begin{array}{c}0.012 \\
(0.203)\end{array}$ & $\begin{array}{c}0.011 \\
(0.200)\end{array}$ & $\begin{array}{c}0.012 \\
(0.530)\end{array}$ & $\begin{array}{c}0.011 \\
(0.525)\end{array}$ & $\begin{array}{r}0.030 \\
(0.451)\end{array}$ \\
\hline IVc & $\begin{array}{l}-0.283 \\
(0.147)\end{array}$ & $\begin{array}{l}-0.114 \\
(0.164)\end{array}$ & $\begin{array}{l}-0.057 \\
(0.158)\end{array}$ & $\begin{array}{l}-0.317 \\
(0.280)\end{array}$ & $\begin{array}{l}-0.295 \\
(0.303)\end{array}$ & $\begin{array}{l}-0.149 \\
(0.335)\end{array}$ \\
\hline
\end{tabular}




\begin{tabular}{|c|c|c|c|c|c|c|}
\hline $\mathrm{V}$ & $\begin{array}{c}0.125 \\
(0.262)\end{array}$ & $\begin{array}{c}0.159 \\
(0.261)\end{array}$ & $\begin{array}{c}0.171 \\
(0.256)\end{array}$ & $\begin{array}{l}-0.326 \\
(0.294)\end{array}$ & $\begin{array}{l}-0.328 \\
(0.295)\end{array}$ & $\begin{array}{l}-0.401 \\
(0.301)\end{array}$ \\
\hline VI & $\begin{array}{l}-0.111 \\
(0.366)\end{array}$ & $\begin{array}{l}-0.093 \\
(0.353)\end{array}$ & $\begin{array}{l}-0.100 \\
(0.359)\end{array}$ & $\begin{array}{l}-0.290 \\
(0.833)\end{array}$ & $\begin{array}{l}-0.282 \\
(0.841)\end{array}$ & $\begin{array}{l}-0.199 \\
(0.631)\end{array}$ \\
\hline VIIlb & $\begin{array}{l}-0.430 \\
(0.380)\end{array}$ & $\begin{array}{c}-0.344 \\
(0.414)\end{array}$ & $\begin{array}{l}-0.342 \\
(0.422)\end{array}$ & & & \\
\hline Military & $\begin{array}{c}0.043 \\
(0.501)\end{array}$ & $\begin{array}{c}0.089 \\
(0.501)\end{array}$ & $\begin{array}{c}0.091 \\
(0.480)\end{array}$ & $\begin{array}{c}0.065 \\
(0.387)\end{array}$ & $\begin{array}{c}0.041 \\
(0.362)\end{array}$ & $\begin{array}{c}0.115 \\
(0.411)\end{array}$ \\
\hline Birth cohort, centered on 1971 , in decades & & $\begin{array}{c}0.051 \\
(0.033)\end{array}$ & $\begin{array}{c}0.047 \\
(0.033)\end{array}$ & & $\begin{array}{c}0.011 \\
(0.064)\end{array}$ & $\begin{array}{c}0.020 \\
(0.060)\end{array}$ \\
\hline Year & & & $\begin{array}{c}0.024 \\
(0.029)\end{array}$ & & & $\begin{array}{l}-0.068 \\
(0.038)\end{array}$ \\
\hline Intercept & $\begin{array}{l}-0.144 \\
(0.117)\end{array}$ & $\begin{array}{l}-0.133 \\
(0.120)\end{array}$ & $\begin{array}{l}-0.015 \\
(0.182)\end{array}$ & $\begin{array}{c}0.369 \\
(0.190)\end{array}$ & $\begin{array}{c}0.368 \\
(0.189)\end{array}$ & $\begin{array}{c}0.016 \\
(0.226)\end{array}$ \\
\hline R-squared & 0.063 & 0.069 & 0.072 & 0.062 & 0.063 & 0.092 \\
\hline $\mathrm{N}$ & 774 & 774 & 774 & 171 & 171 & 171 \\
\hline
\end{tabular}


Table S7. Least squares models for period effects in the racial resentment scale for white-only, nonHispanics, 2006-2020

\begin{tabular}{|c|c|c|c|c|c|c|c|}
\hline & \multirow[b]{3}{*}{ Raw scale } & \multicolumn{3}{|c|}{ All respondents } & \multicolumn{3}{|c|}{$\begin{array}{l}\text { Panel respondents only } \\
\text { for } 2016-2020\end{array}$} \\
\hline & & \multicolumn{3}{|c|}{ Scale residualized with } & \multicolumn{3}{|c|}{ Scale residualized with } \\
\hline & & Model 1 & Model 2 & Model 3 & Model 1 & Model 2 & Model 3 \\
\hline \multirow[t]{2}{*}{2006} & 0.073 & 0.065 & 0.020 & -0.014 & 0.065 & 0.020 & -0.014 \\
\hline & $(0.060)$ & $(0.057)$ & $(0.058)$ & $(0.058)$ & $(0.059)$ & $(0.059)$ & $(0.059)$ \\
\hline \multirow[t]{2}{*}{2008} & 0.090 & 0.078 & 0.043 & 0.020 & 0.078 & 0.043 & 0.020 \\
\hline & $(0.061)$ & $(0.057)$ & $(0.057)$ & $(0.057)$ & $(0.058)$ & $(0.059)$ & $(0.059)$ \\
\hline \multirow[t]{2}{*}{2010} & 0.015 & 0.015 & -0.010 & -0.021 & 0.015 & -0.010 & -0.021 \\
\hline & $(0.060)$ & $(0.057)$ & $(0.057)$ & $(0.057)$ & $(0.059)$ & $(0.059)$ & $(0.059)$ \\
\hline 2012 & -- & -- & -- & -- & -- & -- & -- \\
\hline \multirow[t]{2}{*}{2014} & -0.026 & -0.016 & -0.023 & -0.011 & -0.016 & -0.023 & -0.011 \\
\hline & $(0.066)$ & $(0.063)$ & $(0.063)$ & $(0.063)$ & $(0.065)$ & $(0.064)$ & $(0.064)$ \\
\hline \multirow[t]{2}{*}{2016} & -0.212 & -0.200 & -0.193 & -0.169 & -0.221 & -0.211 & -0.187 \\
\hline & $(0.069)$ & $(0.066)$ & $(0.066)$ & $(0.066)$ & $(0.079)$ & $(0.076)$ & $(0.076)$ \\
\hline \multirow[t]{2}{*}{2018} & -0.327 & -0.310 & -0.294 & -0.258 & -0.255 & -0.240 & -0.204 \\
\hline & $(0.072)$ & $(0.069)$ & $(0.068)$ & $(0.068)$ & $(0.084)$ & $(0.082)$ & $(0.082)$ \\
\hline \multicolumn{8}{|l|}{2020} \\
\hline followup & -0.368 & -0.338 & -0.317 & -0.269 & -0.338 & -0.317 & -0.269 \\
\hline & $(0.075)$ & $(0.071)$ & $(0.071)$ & $(0.071)$ & $(0.069)$ & $(0.068)$ & $(0.068)$ \\
\hline \multirow[t]{2}{*}{ Intercept } & 0.173 & -0.040 & -0.014 & 0.004 & -0.040 & -0.014 & 0.004 \\
\hline & $(0.049)$ & $(0.046)$ & $(0.047)$ & $(0.047)$ & $(0.048)$ & $(0.048)$ & $(0.048)$ \\
\hline R-squared & 0.029 & 0.027 & 0.021 & 0.015 & 0.025 & 0.020 & 0.013 \\
\hline $\mathrm{N}$ & 7854 & 7854 & 7854 & 7854 & 6504 & 6504 & 6504 \\
\hline
\end{tabular}


Table S8. Least squares models for period effects in the racial resentment scale for Hispanic, nonblack respondents, 2006-2020

\begin{tabular}{|c|c|c|c|c|c|c|c|}
\hline & \multirow[b]{2}{*}{ Raw scale } & \multicolumn{3}{|c|}{$\begin{array}{l}\text { All respondents } \\
\text { Scale residualized with }\end{array}$} & \multicolumn{3}{|c|}{$\begin{array}{l}\text { Panel respondents only } \\
\text { for } 2016-2020 \\
\text { Scale residualized with }\end{array}$} \\
\hline & & Model 1 & Model 2 & Model 3 & Model 1 & Model 2 & Model 3 \\
\hline \multirow[t]{2}{*}{2006} & 0.104 & 0.089 & 0.072 & -0.005 & 0.089 & 0.072 & -0.005 \\
\hline & $(0.166)$ & $(0.143)$ & $(0.144)$ & $(0.144)$ & $(0.158)$ & $(0.159)$ & (0.159) \\
\hline \multirow[t]{2}{*}{2008} & -0.022 & -0.051 & -0.064 & -0.115 & -0.051 & -0.064 & -0.115 \\
\hline & $(0.144)$ & $(0.122)$ & $(0.122)$ & $(0.123)$ & $(0.135)$ & $(0.136)$ & $(0.136)$ \\
\hline \multirow[t]{2}{*}{2010} & -0.089 & -0.114 & -0.124 & -0.149 & -0.114 & -0.124 & -0.149 \\
\hline & $(0.132)$ & $(0.116)$ & $(0.118)$ & (0.118) & $(0.129)$ & $(0.131)$ & $(0.131)$ \\
\hline 2012 & -- & -- & -- & -- & -- & -- & -- \\
\hline \multirow[t]{2}{*}{2014} & -0.052 & -0.038 & -0.036 & -0.008 & -0.038 & -0.036 & -0.008 \\
\hline & $(0.163)$ & $(0.156)$ & $(0.160)$ & (0.159) & $(0.173)$ & $(0.177)$ & $(0.177)$ \\
\hline \multirow[t]{2}{*}{2016} & -0.203 & -0.236 & -0.211 & -0.157 & -0.230 & -0.219 & -0.163 \\
\hline & $(0.162)$ & $(0.145)$ & $(0.148)$ & $(0.148)$ & $(0.152)$ & $(0.151)$ & $(0.152)$ \\
\hline \multirow[t]{2}{*}{2018} & -0.381 & -0.377 & -0.362 & -0.282 & -0.232 & -0.206 & -0.127 \\
\hline & $(0.149)$ & (0.139) & $(0.139)$ & (0.139) & $(0.149)$ & $(0.149)$ & $(0.149)$ \\
\hline \multicolumn{8}{|l|}{2020} \\
\hline followup & -0.575 & -0.614 & -0.588 & -0.481 & -0.614 & -0.588 & -0.481 \\
\hline & (0.195) & $(0.184)$ & $(0.182)$ & $(0.182)$ & $(0.171)$ & $(0.168)$ & (0.169) \\
\hline \multirow[t]{2}{*}{ Intercept } & 0.270 & 0.018 & 0.027 & 0.065 & 0.018 & 0.027 & 0.065 \\
\hline & $(0.121)$ & $(0.102)$ & (0.103) & $(0.104)$ & $(0.113)$ & $(0.115)$ & $(0.115)$ \\
\hline R-squared & 0.054 & 0.060 & 0.054 & 0.032 & 0.054 & 0.049 & 0.030 \\
\hline $\mathrm{N}$ & 1568 & 1568 & 1568 & 1568 & 1250 & 1250 & 1250 \\
\hline
\end{tabular}


Table S9. Least squares models for period effects in the racial resentment scale for black-only, nonHispanic respondents, 2006-2020

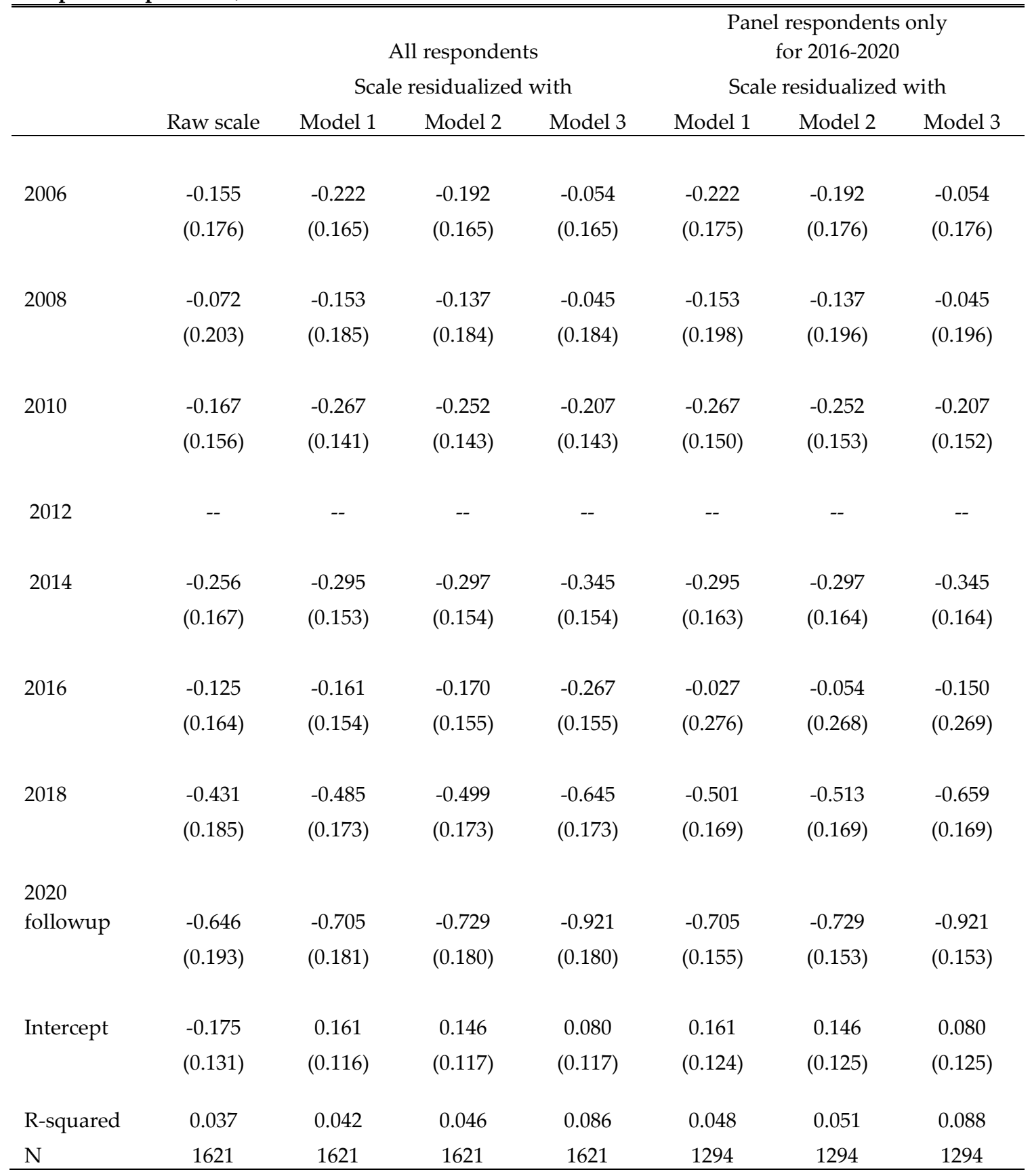


Table S10. Least squares models for period effects in the racial resentment scale for Asian-only, nonHispanic respondents, 2006-2020

\begin{tabular}{|c|c|c|c|c|c|c|c|}
\hline & \multirow[b]{2}{*}{ Raw scale } & \multicolumn{3}{|c|}{$\begin{array}{l}\text { All respondents } \\
\text { Scale residualized with }\end{array}$} & \multicolumn{3}{|c|}{$\begin{array}{l}\text { Panel respondents only } \\
\text { for } 2016-2020 \\
\text { Scale residualized with }\end{array}$} \\
\hline & & Model 1 & Model 2 & Model 3 & Model 1 & Model 2 & Model 3 \\
\hline 2006 & $\begin{array}{c}0.272 \\
(0.237)\end{array}$ & $\begin{array}{c}0.240 \\
(0.219)\end{array}$ & $\begin{array}{c}0.244 \\
(0.218)\end{array}$ & $\begin{array}{l}-0.111 \\
(0.255)\end{array}$ & $\begin{array}{c}0.240 \\
(0.234)\end{array}$ & $\begin{array}{c}0.244 \\
(0.232)\end{array}$ & $\begin{array}{l}-0.111 \\
(0.272)\end{array}$ \\
\hline 2008 & $\begin{array}{c}0.277 \\
(0.194)\end{array}$ & $\begin{array}{c}0.290 \\
(0.181)\end{array}$ & $\begin{array}{c}0.288 \\
(0.180)\end{array}$ & $\begin{array}{c}0.067 \\
(0.231)\end{array}$ & $\begin{array}{c}0.290 \\
(0.193)\end{array}$ & $\begin{array}{c}0.288 \\
(0.192)\end{array}$ & $\begin{array}{c}0.067 \\
(0.247)\end{array}$ \\
\hline 2010 & $\begin{array}{l}-0.170 \\
(0.239)\end{array}$ & $\begin{array}{l}-0.261 \\
(0.214)\end{array}$ & $\begin{array}{l}-0.258 \\
(0.210)\end{array}$ & $\begin{array}{l}-0.366 \\
(0.245)\end{array}$ & $\begin{array}{l}-0.261 \\
(0.229)\end{array}$ & $\begin{array}{l}-0.258 \\
(0.224)\end{array}$ & $\begin{array}{l}-0.366 \\
(0.261)\end{array}$ \\
\hline 2012 & -- & -- & -- & -- & -- & -- & -- \\
\hline 2014 & $\begin{array}{c}0.103 \\
(0.231)\end{array}$ & $\begin{array}{c}0.017 \\
(0.189)\end{array}$ & $\begin{array}{c}0.016 \\
(0.188)\end{array}$ & $\begin{array}{c}0.206 \\
(0.237)\end{array}$ & $\begin{array}{c}0.017 \\
(0.202)\end{array}$ & $\begin{array}{l}0.016 \\
(0.201)\end{array}$ & $\begin{array}{l}0.206 \\
(0.253)\end{array}$ \\
\hline 2016 & $\begin{array}{l}-0.206 \\
(0.385)\end{array}$ & $\begin{array}{l}-0.285 \\
(0.386)\end{array}$ & $\begin{array}{l}-0.285 \\
(0.388)\end{array}$ & $\begin{array}{c}0.023 \\
(0.416)\end{array}$ & $\begin{array}{l}-0.143 \\
(0.447)\end{array}$ & $\begin{array}{l}-0.147 \\
(0.444)\end{array}$ & $\begin{array}{c}0.165 \\
(0.460)\end{array}$ \\
\hline 2018 & $\begin{array}{l}-0.359 \\
(0.672)\end{array}$ & $\begin{array}{l}-0.416 \\
(0.673)\end{array}$ & $\begin{array}{l}-0.426 \\
(0.675)\end{array}$ & $\begin{array}{c}0.013 \\
(0.694)\end{array}$ & $\begin{array}{l}-0.131 \\
(0.630)\end{array}$ & $\begin{array}{l}-0.142 \\
(0.632)\end{array}$ & $\begin{array}{c}0.297 \\
(0.653)\end{array}$ \\
\hline $\begin{array}{l}2020 \\
\text { followup }\end{array}$ & $\begin{array}{l}-0.363 \\
(0.475)\end{array}$ & $\begin{array}{l}-0.382 \\
(0.438)\end{array}$ & $\begin{array}{l}-0.391 \\
(0.438)\end{array}$ & $\begin{array}{c}0.193 \\
(0.462)\end{array}$ & $\begin{array}{l}-0.382 \\
(0.412)\end{array}$ & $\begin{array}{l}-0.391 \\
(0.411)\end{array}$ & $\begin{array}{c}0.193 \\
(0.434)\end{array}$ \\
\hline Intercept & $\begin{array}{c}0.131 \\
(0.145)\end{array}$ & $\begin{array}{l}-0.071 \\
(0.130)\end{array}$ & $\begin{array}{l}-0.073 \\
(0.127)\end{array}$ & $\begin{array}{c}0.105 \\
(0.191)\end{array}$ & $\begin{array}{l}-0.071 \\
(0.138)\end{array}$ & $\begin{array}{l}-0.073 \\
(0.136)\end{array}$ & $\begin{array}{c}0.105 \\
(0.204)\end{array}$ \\
\hline $\begin{array}{l}\text { R-squared } \\
\mathrm{N}\end{array}$ & $\begin{array}{c}0.064 \\
338\end{array}$ & $\begin{array}{c}0.074 \\
338\end{array}$ & $\begin{array}{c}0.075 \\
338\end{array}$ & $\begin{array}{c}0.034 \\
338\end{array}$ & $\begin{array}{c}0.056 \\
285\end{array}$ & $\begin{array}{c}0.057 \\
285\end{array}$ & $\begin{array}{c}0.049 \\
285\end{array}$ \\
\hline
\end{tabular}


Table S11. Least squares models for period effects on scales of prejudice and bigotry as well as opposition to compensatory support for white-only, non-Hispanic respondents, 2006-2020

\begin{tabular}{|c|c|c|c|c|c|c|c|c|}
\hline & \multicolumn{2}{|c|}{$\begin{array}{l}\text { Prejudice and bigotry } \\
\text { (Table } 4 \text { version: } \\
5 \text { items) }\end{array}$} & \multicolumn{2}{|c|}{$\begin{array}{c}\text { Prejudice and bigotry } \\
\text { (Expanded 11-item } \\
\text { version) }\end{array}$} & \multicolumn{2}{|c|}{$\begin{array}{c}\text { Oppose compensatory } \\
\text { support } \\
\text { (Trimmed 2-item } \\
\text { version) }\end{array}$} & \multicolumn{2}{|c|}{$\begin{array}{c}\text { Oppose compensatory } \\
\text { support } \\
\text { (Table } 4 \text { version: } 4 \\
\text { items) }\end{array}$} \\
\hline & Raw & Increment & Raw & Increment & Raw & Increment & Raw & Increment \\
\hline 2006 & $\begin{array}{c}0.061 \\
(0.063)\end{array}$ & $\begin{array}{l}-0.019 \\
(0.059)\end{array}$ & $\begin{array}{c}0.140 \\
(0.067)\end{array}$ & $\begin{array}{c}0.064 \\
(0.064)\end{array}$ & $\begin{array}{r}0.072 \\
(0.053)\end{array}$ & $\begin{array}{r}0.036 \\
(0.051)\end{array}$ & $\begin{array}{l}-0.025 \\
(0.042)\end{array}$ & $\begin{array}{l}-0.055 \\
(0.042)\end{array}$ \\
\hline 2008 & $\begin{array}{c}0.071 \\
(0.063)\end{array}$ & $\begin{array}{c}0.002 \\
(0.059)\end{array}$ & $\begin{array}{c}0.103 \\
(0.062)\end{array}$ & $\begin{array}{c}0.044 \\
(0.059)\end{array}$ & $\begin{array}{c}0.058 \\
(0.050)\end{array}$ & $\begin{array}{c}0.028 \\
(0.048)\end{array}$ & $\begin{array}{l}-0.022 \\
(0.047)\end{array}$ & $\begin{array}{l}-0.047 \\
(0.046)\end{array}$ \\
\hline 2010 & $\begin{array}{c}0.031 \\
(0.062)\end{array}$ & $\begin{array}{l}-0.014 \\
(0.057)\end{array}$ & $\begin{array}{c}0.048 \\
(0.062)\end{array}$ & $\begin{array}{c}0.005 \\
(0.058)\end{array}$ & $\begin{array}{c}0.014 \\
(0.049)\end{array}$ & $\begin{array}{c}0.001 \\
(0.047)\end{array}$ & $\begin{array}{l}-0.046 \\
(0.045)\end{array}$ & $\begin{array}{l}-0.053 \\
(0.044)\end{array}$ \\
\hline 2012 & -- & -- & -- & -- & -- & -- & -- & -- \\
\hline 2014 & $\begin{array}{l}-0.066 \\
(0.066)\end{array}$ & $\begin{array}{l}-0.067 \\
(0.060)\end{array}$ & $\begin{array}{l}-0.068 \\
(0.067)\end{array}$ & $\begin{array}{l}-0.068 \\
(0.063)\end{array}$ & $\begin{array}{l}-0.022 \\
(0.057)\end{array}$ & $\begin{array}{l}-0.021 \\
(0.055)\end{array}$ & $\begin{array}{c}-0.057 \\
(0.045)\end{array}$ & $\begin{array}{l}-0.059 \\
(0.043)\end{array}$ \\
\hline 2016 & $\begin{array}{l}-0.141 \\
(0.063)\end{array}$ & $\begin{array}{l}-0.112 \\
(0.059)\end{array}$ & $\begin{array}{l}-0.138 \\
(0.061)\end{array}$ & $\begin{array}{l}-0.111 \\
(0.060)\end{array}$ & $\begin{array}{l}-0.236 \\
(0.052)\end{array}$ & $\begin{array}{l}-0.226 \\
(0.051)\end{array}$ & $\begin{array}{l}-0.288 \\
(0.045)\end{array}$ & $\begin{array}{l}-0.279 \\
(0.043)\end{array}$ \\
\hline 2018 & $\begin{array}{l}-0.225 \\
(0.065)\end{array}$ & $\begin{array}{l}-0.178 \\
(0.061)\end{array}$ & $\begin{array}{l}-0.237 \\
(0.065)\end{array}$ & $\begin{array}{l}-0.195 \\
(0.064)\end{array}$ & $\begin{array}{l}-0.321 \\
(0.058)\end{array}$ & $\begin{array}{l}-0.302 \\
(0.055)\end{array}$ & $\begin{array}{l}-0.403 \\
(0.049)\end{array}$ & $\begin{array}{l}-0.381 \\
(0.047)\end{array}$ \\
\hline $\begin{array}{l}2020 \\
\text { followup }\end{array}$ & $\begin{array}{l}-0.192 \\
(0.071)\end{array}$ & $\begin{array}{l}-0.118 \\
(0.067)\end{array}$ & $\begin{array}{l}-0.165 \\
(0.069)\end{array}$ & $\begin{array}{l}-0.107 \\
(0.069)\end{array}$ & $\begin{array}{l}-0.357 \\
(0.069)\end{array}$ & $\begin{array}{l}-0.328 \\
(0.066)\end{array}$ & $\begin{array}{l}-0.443 \\
(0.056)\end{array}$ & $\begin{array}{l}-0.412 \\
(0.054)\end{array}$ \\
\hline Intercept & $\begin{array}{c}0.050 \\
(0.049)\end{array}$ & $\begin{array}{c}0.008 \\
(0.044)\end{array}$ & $\begin{array}{c}0.203 \\
(0.050)\end{array}$ & $\begin{array}{l}-0.029 \\
(0.047)\end{array}$ & $\begin{array}{c}0.259 \\
(0.037)\end{array}$ & $\begin{array}{l}-0.017 \\
(0.036)\end{array}$ & $\begin{array}{c}0.342 \\
(0.031)\end{array}$ & $\begin{array}{c}0.039 \\
(0.030)\end{array}$ \\
\hline R-squared & 0.012 & 0.004 & 0.016 & 0.007 & 0.031 & 0.026 & 0.032 & 0.028 \\
\hline $\mathrm{N}$ & 7849 & 7849 & 7849 & 7849 & 7828 & 7828 & 11511 & 11511 \\
\hline
\end{tabular}


Table S12. Least squares models for period effects for individual items on race-related attitudes for white-only, non-Hispanic respondents, 2006-2020

\begin{tabular}{|c|c|c|c|c|c|c|c|c|}
\hline & \multicolumn{2}{|c|}{ RACDIF1 } & \multicolumn{2}{|c|}{ RACDIF2 } & \multicolumn{2}{|c|}{ RACDIF3 } & \multicolumn{2}{|c|}{ RACDIF4 } \\
\hline & Raw & Increment & Raw & Increment & Raw & Increment & Raw & Increment \\
\hline \multirow[t]{2}{*}{2006} & -0.017 & -0.018 & -0.005 & -0.018 & 0.031 & 0.031 & 0.024 & -0.007 \\
\hline & $(0.026)$ & $(0.026)$ & $(0.015)$ & $(0.014)$ & $(0.032)$ & $(0.031)$ & $(0.032)$ & $(0.030)$ \\
\hline \multirow[t]{2}{*}{2008} & -0.020 & -0.025 & 0.008 & -0.004 & 0.048 & 0.050 & 0.035 & 0.012 \\
\hline & $(0.028)$ & $(0.028)$ & $(0.017)$ & $(0.016)$ & $(0.034)$ & $(0.032)$ & $(0.033)$ & $(0.031)$ \\
\hline \multirow[t]{2}{*}{2010} & -0.007 & -0.011 & 0.010 & 0.002 & 0.054 & 0.053 & 0.014 & -0.002 \\
\hline & $(0.027)$ & $(0.027)$ & $(0.016)$ & $(0.015)$ & $(0.031)$ & $(0.029)$ & $(0.032)$ & $(0.030)$ \\
\hline 2012 & -- & -- & -- & -- & -- & -- & -- & -- \\
\hline \multirow[t]{2}{*}{2014} & -0.017 & -0.020 & -0.005 & -0.006 & -0.006 & -0.010 & -0.024 & -0.025 \\
\hline & $(0.030)$ & $(0.029)$ & $(0.016)$ & $(0.015)$ & $(0.032)$ & $(0.030)$ & $(0.034)$ & $(0.032)$ \\
\hline \multirow[t]{2}{*}{2016} & 0.060 & 0.058 & -0.006 & -0.003 & 0.104 & 0.102 & -0.054 & -0.045 \\
\hline & $(0.030)$ & $(0.029)$ & $(0.015)$ & $(0.014)$ & $(0.031)$ & $(0.030)$ & $(0.032)$ & $(0.031)$ \\
\hline \multirow[t]{2}{*}{2018} & 0.080 & 0.082 & -0.013 & -0.007 & 0.095 & 0.089 & -0.109 & -0.093 \\
\hline & $(0.033)$ & $(0.032)$ & $(0.016)$ & $(0.015)$ & $(0.032)$ & $(0.030)$ & $(0.034)$ & $(0.033)$ \\
\hline \multirow{3}{*}{$\begin{array}{l}2020 \\
\text { followup }\end{array}$} & & & & & & & & \\
\hline & 0.087 & 0.091 & -0.019 & -0.007 & 0.055 & 0.047 & -0.090 & -0.064 \\
\hline & $(0.035)$ & $(0.035)$ & $(0.022)$ & $(0.021)$ & $(0.035)$ & $(0.033)$ & $(0.037)$ & $(0.035)$ \\
\hline \multirow[t]{2}{*}{ Intercept } & 0.298 & 0.014 & 0.074 & 0.005 & 0.413 & -0.034 & 0.458 & -0.001 \\
\hline & $(0.021)$ & $(0.021)$ & $(0.013)$ & $(0.012)$ & $(0.024)$ & $(0.023)$ & $(0.025)$ & $(0.023)$ \\
\hline R-squared & 0.009 & 0.010 & 0.001 & 0.000 & 0.005 & 0.005 & 0.010 & 0.005 \\
\hline $\mathrm{N}$ & 7570 & 7570 & 7713 & 7713 & 7670 & 7670 & 7527 & 7527 \\
\hline
\end{tabular}


Table S12 (continued). Least squares models for period effects for individual items on race-related attitudes for white-only, non-Hispanics respondents, 2006-2020

\begin{tabular}{|c|c|c|c|c|c|c|c|c|}
\hline & \multicolumn{2}{|c|}{ AFFRMACT } & \multicolumn{2}{|c|}{$\begin{array}{l}\text { WRKWAYUP } \\
\text { (reversed) }\end{array}$} & \multicolumn{2}{|c|}{$\begin{array}{l}\text { Intelligent- } \\
\text { unintelligent } \\
\text { difference }\end{array}$} & \multicolumn{2}{|c|}{$\begin{array}{c}\text { Hard working - lazy } \\
\text { difference }\end{array}$} \\
\hline & Raw & Increment & Raw & Increment & Raw & Increment & Raw & Increment \\
\hline 2006 & $\begin{array}{c}0.082 \\
(0.054)\end{array}$ & $\begin{array}{c}0.054 \\
(0.052)\end{array}$ & $\begin{array}{c}0.050 \\
(0.064)\end{array}$ & $\begin{array}{l}-0.002 \\
(0.061)\end{array}$ & $\begin{array}{c}0.028 \\
(0.065)\end{array}$ & $\begin{array}{l}-0.024 \\
(0.063)\end{array}$ & $\begin{array}{c}0.065 \\
(0.090)\end{array}$ & $\begin{array}{l}-0.012 \\
(0.087)\end{array}$ \\
\hline 2008 & $\begin{array}{c}0.055 \\
(0.049)\end{array}$ & $\begin{array}{c}0.037 \\
(0.047)\end{array}$ & $\begin{array}{c}0.058 \\
(0.068)\end{array}$ & $\begin{array}{l}-0.010 \\
(0.064)\end{array}$ & $\begin{array}{c}0.022 \\
(0.069)\end{array}$ & $\begin{array}{l}-0.025 \\
(0.068)\end{array}$ & $\begin{array}{l}-0.029 \\
(0.084)\end{array}$ & $\begin{array}{l}-0.096 \\
(0.082)\end{array}$ \\
\hline 2010 & $\begin{array}{c}0.038 \\
(0.051)\end{array}$ & $\begin{array}{c}0.031 \\
(0.048)\end{array}$ & $\begin{array}{l}-0.016 \\
(0.066)\end{array}$ & $\begin{array}{c}0.039 \\
(0.063)\end{array}$ & $\begin{array}{c}0.007 \\
(0.067)\end{array}$ & $\begin{array}{l}-0.022 \\
(0.066)\end{array}$ & $\begin{array}{l}-0.056 \\
(0.090)\end{array}$ & $\begin{array}{l}-0.098 \\
(0.089)\end{array}$ \\
\hline 2012 & -- & -- & -- & -- & -- & -- & -- & -- \\
\hline 2014 & $\begin{array}{c}0.014 \\
(0.053)\end{array}$ & $\begin{array}{c}0.010 \\
(0.051)\end{array}$ & $\begin{array}{l}-0.054 \\
(0.076)\end{array}$ & $\begin{array}{c}0.051 \\
(0.071)\end{array}$ & $\begin{array}{l}-0.053 \\
(0.067)\end{array}$ & $\begin{array}{l}-0.058 \\
(0.066)\end{array}$ & $\begin{array}{l}-0.061 \\
(0.088)\end{array}$ & $\begin{array}{l}-0.065 \\
(0.086)\end{array}$ \\
\hline 2016 & $\begin{array}{l}-0.162 \\
(0.052)\end{array}$ & $\begin{array}{l}-0.163 \\
(0.051)\end{array}$ & $\begin{array}{l}-0.293 \\
(0.077)\end{array}$ & $\begin{array}{c}0.276 \\
(0.074)\end{array}$ & $\begin{array}{l}-0.125 \\
(0.062)\end{array}$ & $\begin{array}{l}-0.113 \\
(0.060)\end{array}$ & $\begin{array}{l}-0.200 \\
(0.084)\end{array}$ & $\begin{array}{l}-0.183 \\
(0.081)\end{array}$ \\
\hline 2018 & $\begin{array}{l}-0.203 \\
(0.060)\end{array}$ & $\begin{array}{l}-0.200 \\
(0.058)\end{array}$ & $\begin{array}{l}-0.418 \\
(0.081)\end{array}$ & $\begin{array}{c}0.387 \\
(0.076)\end{array}$ & $\begin{array}{l}-0.064 \\
(0.067)\end{array}$ & $\begin{array}{l}-0.039 \\
(0.067)\end{array}$ & $\begin{array}{l}-0.244 \\
(0.093)\end{array}$ & $\begin{array}{c}-0.204 \\
(0.091)\end{array}$ \\
\hline $\begin{array}{l}2020 \\
\text { followup }\end{array}$ & $\begin{array}{l}-0.175 \\
(0.074)\end{array}$ & $\begin{array}{l}-0.168 \\
(0.072)\end{array}$ & $\begin{array}{l}-0.542 \\
(0.086)\end{array}$ & $\begin{array}{c}0.484 \\
(0.081)\end{array}$ & $\begin{array}{l}-0.058 \\
(0.084)\end{array}$ & $\begin{array}{l}-0.018 \\
(0.083)\end{array}$ & $\begin{array}{l}-0.172 \\
(0.101)\end{array}$ & $\begin{array}{l}-0.113 \\
(0.102)\end{array}$ \\
\hline Intercept & $\begin{array}{c}3.406 \\
(0.037)\end{array}$ & $\begin{array}{l}-0.031 \\
(0.035)\end{array}$ & $\begin{array}{c}3.307 \\
(0.050)\end{array}$ & $\begin{array}{l}-0.007 \\
(0.047)\end{array}$ & $\begin{array}{c}7.349 \\
(0.053)\end{array}$ & $\begin{array}{c}0.018 \\
(0.052)\end{array}$ & $\begin{array}{c}7.655 \\
(0.069)\end{array}$ & $\begin{array}{c}0.052 \\
(0.067)\end{array}$ \\
\hline R-squared & 0.014 & $\begin{array}{l}0.012 \\
7511\end{array}$ & $\begin{array}{l}0.032 \\
7784\end{array}$ & $\begin{array}{l}0.026 \\
7784\end{array}$ & $\begin{array}{l}0.003 \\
7622\end{array}$ & $\begin{array}{l}0.001 \\
7622\end{array}$ & $\begin{array}{l}0.006 \\
7622\end{array}$ & $\begin{array}{l}0.003 \\
7622\end{array}$ \\
\hline
\end{tabular}


Table S12 (continued). Least squares models for period effects for individual items on race-related attitudes for white-only, non-Hispanic respondents, 2006-2020

\begin{tabular}{|c|c|c|c|c|c|c|c|c|}
\hline & \multicolumn{2}{|c|}{ LIVEBLKS } & \multicolumn{2}{|c|}{$\begin{array}{l}\text { Oppose intermarriage } \\
\text { (Tesler OFR coding) }\end{array}$} & \multicolumn{2}{|c|}{ DISCAFF } & \multicolumn{2}{|c|}{ LETIN1A } \\
\hline & Raw & Increment & Raw & Increment & Raw & Increment & Raw & Increment \\
\hline 2006 & $\begin{array}{c}0.087 \\
(0.056)\end{array}$ & $\begin{array}{c}0.059 \\
(0.055)\end{array}$ & $\begin{array}{c}0.323 \\
(0.094)\end{array}$ & $\begin{array}{c}0.188 \\
(0.091)\end{array}$ & $\begin{array}{l}-0.111 \\
(0.042)\end{array}$ & $\begin{array}{l}-0.071 \\
(0.040)\end{array}$ & $\begin{array}{c}0.178 \\
(0.072)\end{array}$ & $\begin{array}{c}0.142 \\
(0.067)\end{array}$ \\
\hline 2008 & $\begin{array}{c}0.003 \\
(0.049)\end{array}$ & $\begin{array}{l}-0.019 \\
(0.049)\end{array}$ & $\begin{array}{c}0.122 \\
(0.095)\end{array}$ & $\begin{array}{c}0.013 \\
(0.091)\end{array}$ & $\begin{array}{l}-0.021 \\
(0.043)\end{array}$ & $\begin{array}{c}0.014 \\
(0.042)\end{array}$ & $\begin{array}{c}0.157 \\
(0.067)\end{array}$ & $\begin{array}{c}0.132 \\
(0.064)\end{array}$ \\
\hline 2010 & $\begin{array}{c}0.031 \\
(0.051)\end{array}$ & $\begin{array}{c}0.016 \\
(0.051)\end{array}$ & $\begin{array}{l}-0.007 \\
(0.089)\end{array}$ & $\begin{array}{l}-0.084 \\
(0.084)\end{array}$ & $\begin{array}{l}-0.001 \\
(0.044)\end{array}$ & $\begin{array}{c}0.004 \\
(0.042)\end{array}$ & $\begin{array}{c}0.114 \\
(0.070)\end{array}$ & $\begin{array}{c}0.096 \\
(0.064)\end{array}$ \\
\hline 2012 & -- & -- & -- & -- & -- & -- & -- & -- \\
\hline 2014 & $\begin{array}{c}0.015 \\
(0.055)\end{array}$ & $\begin{array}{c}0.015 \\
(0.054)\end{array}$ & $\begin{array}{l}-0.159 \\
(0.093)\end{array}$ & $\begin{array}{l}-0.166 \\
(0.086)\end{array}$ & $\begin{array}{l}-0.014 \\
(0.043)\end{array}$ & $\begin{array}{l}-0.019 \\
(0.040)\end{array}$ & $\begin{array}{l}-0.002 \\
(0.068)\end{array}$ & $\begin{array}{c}0.011 \\
(0.065)\end{array}$ \\
\hline 2016 & $\begin{array}{l}-0.072 \\
(0.047)\end{array}$ & $\begin{array}{l}-0.066 \\
(0.048)\end{array}$ & $\begin{array}{l}-0.222 \\
(0.083)\end{array}$ & $\begin{array}{l}-0.187 \\
(0.079)\end{array}$ & $\begin{array}{c}0.045 \\
(0.043)\end{array}$ & $\begin{array}{c}0.034 \\
(0.041)\end{array}$ & $\begin{array}{l}-0.117 \\
(0.069)\end{array}$ & $\begin{array}{c}-0.091 \\
(0.064)\end{array}$ \\
\hline 2018 & $\begin{array}{l}-0.111 \\
(0.049)\end{array}$ & $\begin{array}{l}-0.098 \\
(0.050)\end{array}$ & $\begin{array}{l}-0.373 \\
(0.079)\end{array}$ & $\begin{array}{l}-0.309 \\
(0.076)\end{array}$ & $\begin{array}{c}0.073 \\
(0.044)\end{array}$ & $\begin{array}{c}0.033 \\
(0.043)\end{array}$ & $\begin{array}{l}-0.330 \\
(0.072)\end{array}$ & $\begin{array}{l}-0.288 \\
(0.066)\end{array}$ \\
\hline $\begin{array}{l}2020 \\
\text { followup }\end{array}$ & $\begin{array}{l}-0.081 \\
(0.057)\end{array}$ & $\begin{array}{l}-0.064 \\
(0.057)\end{array}$ & $\begin{array}{l}-0.515 \\
(0.081)\end{array}$ & $\begin{array}{l}-0.422 \\
(0.076)\end{array}$ & $\begin{array}{l}-0.006 \\
(0.045)\end{array}$ & $\begin{array}{l}-0.044 \\
(0.044)\end{array}$ & $\begin{array}{l}-0.400 \\
(0.087)\end{array}$ & $\begin{array}{c}-0.337 \\
(0.079)\end{array}$ \\
\hline Intercept & $\begin{array}{c}2.935 \\
(0.037)\end{array}$ & $\begin{array}{l}-0.014 \\
(0.036)\end{array}$ & $\begin{array}{c}1.914 \\
(0.069)\end{array}$ & $\begin{array}{l}-0.030 \\
(0.064)\end{array}$ & $\begin{array}{c}2.220 \\
(0.033)\end{array}$ & $\begin{array}{c}0.014 \\
(0.031)\end{array}$ & $\begin{array}{c}3.648 \\
(0.053)\end{array}$ & $\begin{array}{c}-0.094 \\
(0.049)\end{array}$ \\
\hline $\begin{array}{l}\text { R-squared } \\
\mathrm{N}\end{array}$ & $\begin{array}{l}0.005 \\
7779\end{array}$ & $\begin{array}{l}0.003 \\
7779\end{array}$ & $\begin{array}{l}0.038 \\
7834\end{array}$ & $\begin{array}{l}0.021 \\
7834\end{array}$ & $\begin{array}{l}0.006 \\
7554\end{array}$ & $\begin{array}{l}0.003 \\
7554\end{array}$ & $\begin{array}{l}0.036 \\
7684\end{array}$ & $\begin{array}{l}0.028 \\
7684\end{array}$ \\
\hline
\end{tabular}


Table S12 (continued). Least squares models for period effects for individual items on race-related attitudes for white-only, non-Hispanic respondents, 2006-2020

HELPBLK

\begin{tabular}{|c|c|c|}
\hline & Raw & Increment \\
\hline 2006 & $\begin{array}{l}-0.218 \\
(0.059)\end{array}$ & $\begin{array}{l}-0.226 \\
(0.059)\end{array}$ \\
\hline 2008 & $\begin{array}{l}-0.137 \\
(0.072)\end{array}$ & $\begin{array}{c}-0.146 \\
(0.071)\end{array}$ \\
\hline 2010 & $\begin{array}{l}-0.128 \\
(0.069)\end{array}$ & $\begin{array}{l}-0.129 \\
(0.068)\end{array}$ \\
\hline 2012 & -- & -- \\
\hline 2014 & $\begin{array}{l}-0.121 \\
(0.062)\end{array}$ & $\begin{array}{l}-0.129 \\
(0.061)\end{array}$ \\
\hline 2016 & $\begin{array}{l}-0.423 \\
(0.064)\end{array}$ & $\begin{array}{l}-0.428 \\
(0.063)\end{array}$ \\
\hline 2018 & $\begin{array}{l}-0.544 \\
(0.072)\end{array}$ & $\begin{array}{l}-0.544 \\
(0.070)\end{array}$ \\
\hline $\begin{array}{l}2020 \\
\text { followup }\end{array}$ & $\begin{array}{l}-0.706 \\
(0.085)\end{array}$ & $\begin{array}{c}-0.699 \\
(0.083)\end{array}$ \\
\hline Intercept & $\begin{array}{r}3.955 \\
(0.043)\end{array}$ & $\begin{array}{c}0.128 \\
(0.042)\end{array}$ \\
\hline $\begin{array}{l}\text { R-squared } \\
N\end{array}$ & $\begin{array}{l}0.036 \\
7696\end{array}$ & $\begin{array}{l}0.036 \\
7696\end{array}$ \\
\hline
\end{tabular}


Table S13 (for Comparison with Table 5). Raw and incremental change per year for the period effects on racial attitudes from 2010 through 2020, white-only, non-Hispanic respondents

\begin{tabular}{|c|c|c|c|c|c|c|}
\hline & \multicolumn{2}{|c|}{ Racial resentment } & \multicolumn{2}{|c|}{$\begin{array}{c}\text { Prejudice and bigotry } \\
\text { (5-item) }\end{array}$} & \multicolumn{2}{|c|}{$\begin{array}{l}\text { Oppose compensatory } \\
\text { support (4-item) }\end{array}$} \\
\hline & Raw & Increment & Raw & Increment & Raw & Increment \\
\hline \multicolumn{7}{|l|}{ Gender: } \\
\hline \multirow[t]{2}{*}{ Male } & -0.055 & -0.045 & -0.036 & -0.022 & -0.058 & -0.053 \\
\hline & $(0.009)$ & $(0.009)$ & $(0.008)$ & $(0.009)$ & $(0.008)$ & $(0.007)$ \\
\hline \multirow[t]{2}{*}{ Female } & -0.057 & -0.046 & -0.034 & -0.016 & -0.056 & -0.050 \\
\hline & $(0.009)$ & $(0.008)$ & $(0.007)$ & $(0.007)$ & $(0.007)$ & $(0.006)$ \\
\hline \multicolumn{7}{|l|}{ Educational attainment: } \\
\hline \multirow[t]{2}{*}{ No HS diploma } & -0.035 & -0.031 & -0.036 & -0.028 & -0.042 & -0.039 \\
\hline & $(0.021)$ & $(0.020)$ & $(0.023)$ & $(0.023)$ & $(0.014)$ & $(0.014)$ \\
\hline \multirow[t]{2}{*}{ HS diploma } & -0.049 & -0.043 & -0.035 & -0.025 & -0.045 & -0.042 \\
\hline & $(0.009)$ & $(0.008)$ & $(0.008)$ & $(0.008)$ & $(0.006)$ & $(0.006)$ \\
\hline \multirow[t]{2}{*}{ Some college } & -0.068 & -0.059 & -0.060 & -0.046 & -0.043 & -0.040 \\
\hline & $(0.019)$ & $(0.018)$ & $(0.013)$ & $(0.014)$ & $(0.015)$ & $(0.015)$ \\
\hline \multirow[t]{2}{*}{ Bachelor's degree } & -0.062 & -0.057 & -0.019 & -0.009 & -0.078 & -0.074 \\
\hline & $(0.012)$ & $(0.012)$ & $(0.012)$ & $(0.012)$ & $(0.010)$ & $(0.009)$ \\
\hline \multirow[t]{2}{*}{ Graduate degree } & -0.040 & -0.029 & -0.009 & 0.008 & -0.059 & -0.054 \\
\hline & $(0.019)$ & $(0.020)$ & $(0.011)$ & $(0.012)$ & $(0.014)$ & $(0.014)$ \\
\hline \multicolumn{7}{|l|}{ Party Identification: } \\
\hline \multirow[t]{2}{*}{ Democrat (excluding leaners) } & -0.122 & -0.104 & -0.069 & -0.046 & -0.118 & -0.106 \\
\hline & $(0.011)$ & $(0.010)$ & $(0.011)$ & $(0.011)$ & $(0.010)$ & $(0.009)$ \\
\hline \multicolumn{7}{|l|}{ Independents (including } \\
\hline \multirow[t]{2}{*}{ learners) } & -0.057 & -0.046 & -0.025 & -0.008 & -0.055 & -0.048 \\
\hline & $(0.009)$ & $(0.009)$ & $(0.009)$ & $(0.009)$ & $(0.008)$ & $(0.008)$ \\
\hline \multirow[t]{2}{*}{ Republicans (excluding leaners) } & -0.014 & -0.009 & -0.024 & -0.015 & -0.010 & -0.008 \\
\hline & $(0.008)$ & $(0.008)$ & $(0.010)$ & $(0.009)$ & $(0.005)$ & $(0.005)$ \\
\hline $\mathrm{N}$ for gender and education & 7854 & 7854 & 7849 & 7849 & 11511 & 11511 \\
\hline $\mathrm{N}$ for party identification & 7599 & 7599 & 7594 & 7594 & 11124 & 11124 \\
\hline
\end{tabular}

